\title{
miRNA Inhibition in Tissue Engineering and Regenerative Medicine
}

\author{
Kelsey R. Beavers ${ }^{1}$, Christopher E. Nelson ${ }^{2}$, Craig L. Duvall ${ }^{1,3^{*}}$
}

${ }^{1}$ Interdisciplinary Graduate Program in Materials Science, Vanderbilt University, Nashville, Tennessee 37235, USA

${ }^{2}$ Department of Biomedical Engineering, Duke University, Durham, North Carolina 27708, USA

${ }^{3}$ Department of Biomedical Engineering, Vanderbilt University, Nashville, Tennessee 37235, USA

*Corresponding Author: Phone: (615-322-3598); email:craig.duvall@vanderbilt.edu

\begin{abstract}
MicroRNA (miRNA) are noncoding RNA that provide an endogenous negative feedback mechanism for translation of messenger RNA (mRNA) into protein. Single miRNAs can regulate hundreds of mRNAs, enabling miRNAs to orchestrate robust biological responses by simultaneously impacting multiple gene networks. MiRNAs can act as master regulators of normal and pathological tissue development, homeostasis, and repair, which has recently motivated expanding efforts toward development of technologies for therapeutically modulating miRNA activity for regenerative medicine and tissue engineering applications. This review highlights the tools currently available for miRNA inhibition and their recent therapeutic applications for improving tissue repair.
\end{abstract}


Keywords: miRNA; anti-miR; miRNA inhibition; Tissue Engineering; Regenerative Medicine

\section{Table of Contents}

1. Introduction

2. Anti-miR mechanisms

3. Classes of anti-miRs

3.1. Anti-miR oligonucleotides

3.2. miRNA sponges

3.3 Small molecule inhibitors

4. Delivery considerations for anti-miR therapies

4.1. Non-viral delivery

4.2. Viral delivery

4.3. Scaffold-mediated delivery

5. Regenerative medicine targets

5.1. Bone regeneration

5.2. Liver regeneration

5.3. Kidney regeneration

5.4. Muscle regeneration

5.4.1. Skeletal muscle regeneration

5.4.2. Cardiac muscle regeneration

5.5. Wound healing

5.5.1. Inflammation

5.5.2. Proliferation

5.5.3. Angiogenesis

5.5.4 Scarless healing

6. Conclusions and clinical outlook 


\section{Introduction}

MicroRNA (miRNA) are noncoding RNA molecules that are expressed in both animal and plant cells to provide a mechanism for negative regulation of messenger RNA (mRNA) translation into protein [1]. Delivery of synthetic siRNA or antisense oligonucleotides have been heavily investigated for therapeutic post-transcriptional inhibition of target genes [2-6]. These exogenously delivered molecules are effectively miRNA mimics but are designed to silence a single mRNA as specifically and potently as possible in order to produce predictable pharmacodynamics; therefore, one must design and deliver multiple antisense oligonucleotides or siRNA to modulate more than one gene. On the other hand, endogenous miRNA are often cross-reactive with hundreds of different mRNA with partial, but not necessarily $100 \%$ complementarity [7]. As a result, miRNA can orchestrate robust, comprehensive responses by simultaneously affecting a broad network of related genes. The prevalence of miRNA posttranscription regulation is very high, and it is estimated that miRNAs regulate greater than $60 \%$ of human protein encoding genes [8]. Specific miRNAs are dysregulated in many pathological settings [1, 9-11], and miRNAs have recently emerged as a new class of disease biomarkers [12-14]. There is also a tremendous opportunity to develop new classes of pharmaceuticals that specifically modulate miRNA pathways in order to manipulate multiple, related genes with a single intervention. In the context of therapy, there is potential both for delivery of miRNA molecules, as thoroughly reviewed in the other articles within this issue, and also for delivery of miRNA inhibitory therapeutics (known as anti-miRs), as reviewed here.

Therapeutic inhibition of miRNA represents a relatively unexplored but potentially powerful approach to modulate stem cell differentiation, to control host cell function as they infiltrate tissue engineering constructs, and to therapeutically normalize activity of gene networks required for progression of endogenous repair processes. Availability of robust tools for measuring and modulating miRNA activity is critical to understanding the roles of specific miRNA in normal cell and developmental biology and to discover miRNAs that are promising 
therapeutic targets. Clinical translation requires optimization of anti-miR chemistry and engineering of carrier technologies to overcome in vivo delivery barriers not often considered during the development of the in vitro research tools and reagents. Recently, progress has been made to this end, and anti-miRs are currently under development for a broad range of clinical indications. Some of the most advanced anti-miR therapies have been tested in nonhuman primate preclinical trials for hepatitis C [15] and atherosclerosis [16], as well as in human clinical trials for hepatitis $C$ [17]. Based on the promise of these studies and the knowledge that miRNA play fundamental roles in cellular-fate processes essential in tissue development, homeostasis, and repair [7, 18], there is rapid growth in research aimed at harnessing anti-miRs for regenerative medicine and tissue engineering applications. This review will overview current miRNA inhibitor designs, discuss delivery challenges, and highlight miRNA targets that have shown therapeutic potential in the context of tissue engineering and regenerative medicine.

\section{Anti-miR mechanisms}

There are multiple stages during the biogenesis of miRNA that represent potential points of intervention for anti-miRs (Figure 1). Briefly, the first step in miRNA production is transcription into long primary RNA transcripts known as pri-miRNAs. The pri-miRNAs are cleaved by Drosha in the nucleus into a 70 base pair pre-miRNA hairpin intermediate. Pre-miRNA are then exported to the cytoplasm and processed by Dicer ribonucleases into mature, double-stranded miRNA that are between 18 and 25 nucleotides in length. The mature miRNA interacts with the proteins that comprise the RNA-induced silencing complex (RISC), which separates the guide strand of the mature miRNA from the passenger strand, retaining the guide strand to form an active RISC [19-20]. The miRNA guide strand then binds to complementary mRNA and enables target mRNA cleavage by the RISC-associated endonuclease Argonaut2 (Ago2) (Figure 1A) [20]. As illustrated in Figure 1, anti-miRs can be designed to inhibit either the mature miRNA in the active RISC complex, or any of its precursors [21]. 
Most miRNA inhibitors are designed to bind to and inhibit the activity of the mature miRNA guide strand once it is loaded into the RISC (Figure 1D-F), and these classes of anti-miRs are summarized in the next section [22]. However, there has also been proof of successful inhibition of the mature miRNA precursors. Targeting pri- and pre-miRNAs can be advantageous because they contain sequences that are not present in mature miRNA; these sequences are typically not conserved among different miRNAs (even from the same family) [23]. Targeting miRNA precursors therefore enables better discrimination among miRNAs that possess similar mature sequences [23]. Kloosterman et al. showed that miRNA activity can be inhibited by targeting the pri-miRNA or the pre-miRNA (Figure 1B and 1C). Anti-miRs complementary to the pri-miRNA Drosha cleavage site inhibited processing into pre-miRNA, while those complementary to the Dicer-cleavage site on the stem of pre-miRNA inhibited Dicer processing into mature miRNA. Both tactics resulted in robust inhibition of mature miRNA formation in zebrafish [24]. Another approach by Lee et al. demonstrated that delivery of double-stranded siRNA against the loop region of pre-miRNA can deplete the pool of mature miRNA in vitro. However, this approach did not work in all cell types tested, and was less potent in comparison to inhibitory strategies that target mature miRNA [21]. The potential disadvantages in targeting miRNA precursors are that they are relatively transient species during processing to mature miRNA and that not all miRNAs are equally susceptible to inhibition at the level of pre- or pri-RNA [24]. In addition, pri-miRNAs are especially difficult targets because they require inhibitor access to the nucleus.

Another alternative approach to targeting mature miRNA known as "blockmir" technology has also shown promise. Blockmirs are $\sim 15 \mathrm{mer}$ antisense oligonucleotides that are instead targeted to the mRNA and function to target and block miRNA binding sites (Figure 1G) [25]. These molecules bind to untranslated regions of mRNA where miRNA bind, thus blocking miRNA-induced mRNA degradation while retaining the ability of the mRNA to be translated into protein [26]. In a recent application of a blockmir designed against the miR-27 binding site on VE-cadherin mRNA, the authors achieved selective up-regulation of VE-cadherin but not two 
other verified miR-27 targets, PPARY and SEMA6A. Ultimately, this gene-specific miRNA inhibition strategy stabilized vascular endothelial cell-cell junctions, regulated vascular leakage, and enhanced recovery from ischemic limb injury in mice [25]. Because blockmirs target individual mRNAs, they may provide a means to reduce off-target effects and to achieve more predictable pharmacodynamics than anti-miRs that block all miR activities. This better specificity may aid clinical translation of anti-miR therapeutics for regenerative medicine, but it also abrogates the ability to develop therapeutics that simultaneously regulate multiple genes.

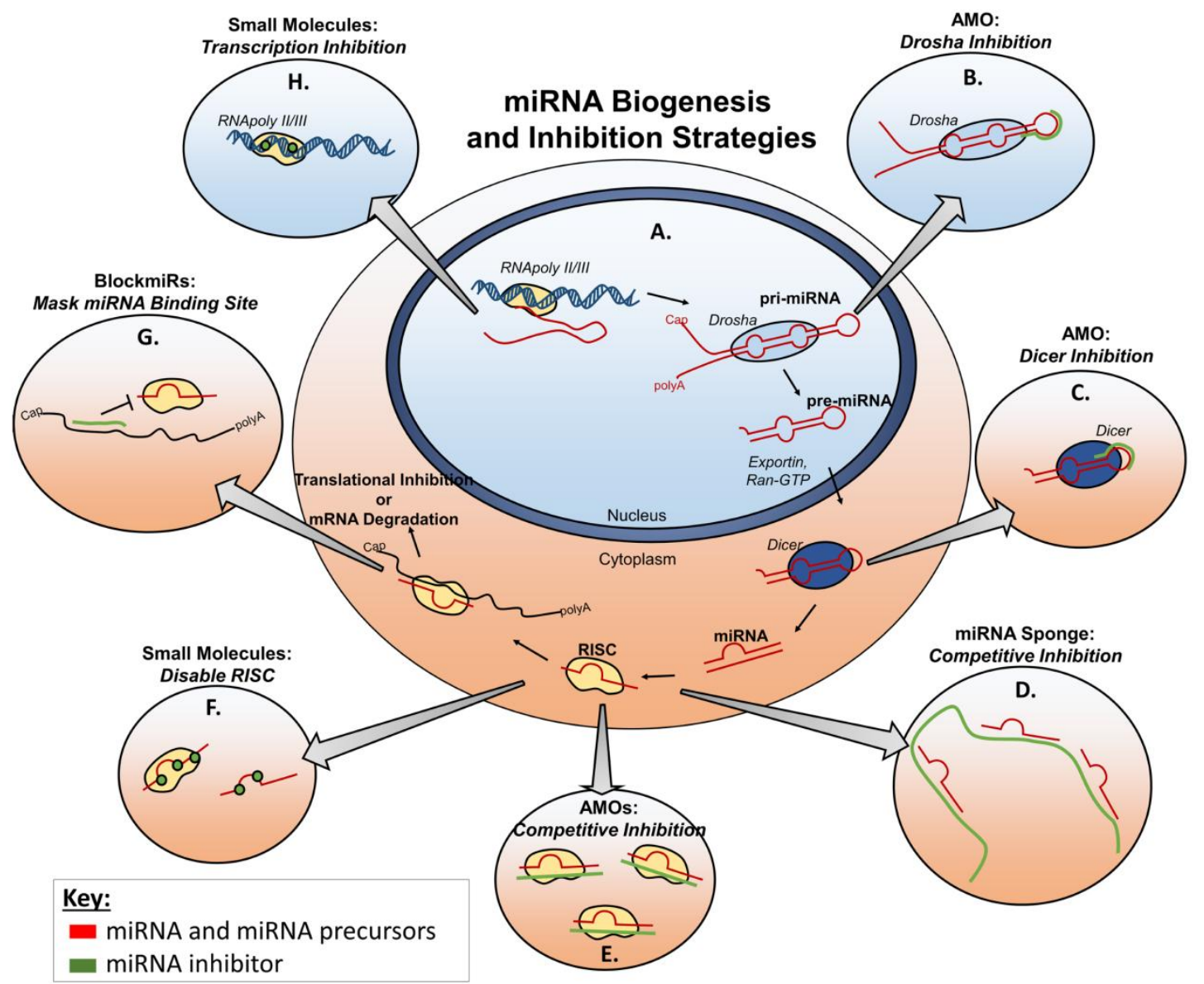

Figure1. Sites of intervention for different anti-miRs along (A) the miRNA biogenesis pathway. Anti-miRNA oligos (AMOs) are typically single stranded oligos that are introduced exogenously into the cell and can bind to (B) pri-miRNA to inhibit Drosha activity or (C) pre-miRNA to inhibit Dicer cleavage. (D) miRNA sponges are expressed as transgenes that contain multiple miRNA 
binding sites for competitive inhibition of binding to mRNA. (E) AMOs are most commonly designed to bind to and inhibit mature miRNA. (G) Blockmirs are oligonucleotides that block miRNA activity by specifically masking the 3' UTR of target mRNA. Small molecule miRNA inhibitors act by either $(\mathbf{F})$ inhibiting the formation of active RISC, or $(\mathbf{H})$ preventing expression of miRNA genes into pri-miRNA.

\section{Classes of anti-miRs}

The two primary classes of miRNA inhibitors are oligonucleotides (including both conventional nucleic acids and synthetic nucleic acid analogues) and small-molecules. This section introduces the portfolio of technologies currently available for modulation of miRNA activity for applications in tissue engineering and regenerative medicine.

\subsection{Anti-miR oligonucleotides}

Anti-miRNA oligonucleotides (AMOs) are the most prevalent class of miRNA inhibitors. There are several variants of AMOs utilized as anti-miRs, but they are all generally designed to be complementary to the full mature miRNA, such that they bind to and sterically inhibit the binding of the RISC-loaded miRNA guide strand to target mRNAs (Figure 1E) [27]. Effective AMOs must have high specificity and strong binding affinity to target miRNA [1]. The first AMO developed was a DNA oligo of complementary sequence and equal length to the target miRNA [28]. Later work revealed that the instability of unmodified DNA AMOs in serum severely limits their effectiveness in vivo [29]. Subsequent AMO designs have, therefore, focused on increasing AMO stability and endonuclease resistance, in addition to improving binding affinity to miRNA.

Most AMOs are single stranded nucleic acids with modifications to RNA backbone chemistry (Figure 2A) incorporated to improve binding and/or impart nuclease resistance. The earliest tested AMO modifications included methylation of nucleoside ribose 2' hydroxyl groups (Figure 2B). This "OMe" modification improves RNA binding affinity and contributes a modest 
improvement in nuclease resistance compared to unmodified sequences. However, OMe modified AMOs still suffer from relatively poor stability in serum [22]. Replacing the phosphodiester bonds in the AMO backbone with phosphorothiolate (PS) linkages is a more effective way of conferring nuclease resistance, but it also results in decreased AMO binding to target miRNA (Figure 2D) [30]. An additional modifier, N,N-diethyl-4-(4-nitronaphthalen-1-ylazo)phenylamine, dubbed "ZEN" increases the binding affinity and nuclease resistance by enhancing steric blocking when positioned near the ends of OMe-modified RNA (Figure 2E) [27]. Antagomirs are another AMO derivative designed to improve the biostability and bioavailability of OMe oligos [31-32]. Antagomirs possess a 3' end conjugation to cholesterol which imparts nuclease resistance [32]. As an added benefit, this hydrophobic cholesterol moiety enables antagomirs to better traverse the cell membrane and enter cells without the aid of a delivery vector [31]. However, clinical translation of antagomirs is limited as they require relatively high doses to achieve miRNA inhibition (up to $80 \mathrm{mg} / \mathrm{kg}$ in a mouse model) [31], and have shown concerning off-target effects in vivo, as evidenced by discrepancies in the cardiac phenotypes of animals with genetic depletions of miR-21 and miR-133a and those treated with antagomirs against miR-21 and miR-133a [31, 33-35].

The most effective, high-affinity $A M O$ designs rely on highly-modified, synthetic oligonucleotide chemistries: locked nucleic acids (LNA), phosphorodiamidate morpholino oligonucleotides (PMOs), and peptide nucleic acids (PNA). LNA contain a methylene bridge between the 2'-O and 4'C of ribose to "lock" it into a configuration which is optimal for hybridization. LNA are also highly resistant to nuclease degradation (Figure 2C) [36]. Consequently, LNA-based AMOs show higher anti-miR activity at lower doses compared with the equivalent antagomir [37]. PMOs, another AMO derivative, substitute ribose with 6membered morpholine rings, and phosphorodiamidates are used rather than phosphodiester bonds, making the overall molecule neutrally-charged (Figure 2F) [38]. These modifications sterically hinder nuclease binding and thus prevent enzymatic degradation of PMOs, but PMOs 
exhibit lower binding affinity for miRNA compared to LNA [38-39]. The binding affinity of PNA is the result of PNA's chimeric structure, in which nucleobases are spaced along a peptide backbone (Figure 2G) [40]. PNA's synthetic structure imparts both nuclease and protease resistance to PNA AMOs [41], while PNA's charge neutrality allows it to bind with high affinity and specificity to miRNA targets [42]. In general, the AMO target miRNA binding affinity listed from lowest to highest affinity follows the order: DNA<OMe oligos<PS-modified OMe oligos $<Z E N-$ modified OMe oligos $<P M O<P N A \approx L N A[27,37-39]$. The nuclease resistance imparted from these modification listed from lowest to highest stability follows the order DNA<OMe oligos<ZEN-modified OMe oligos<PS-modified OMe oligos $<$ PMO $\approx$ PNA $\approx$ LNA [27, 43-44]. 


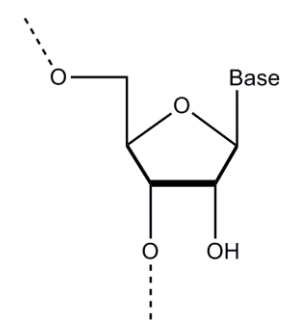

A. RNA

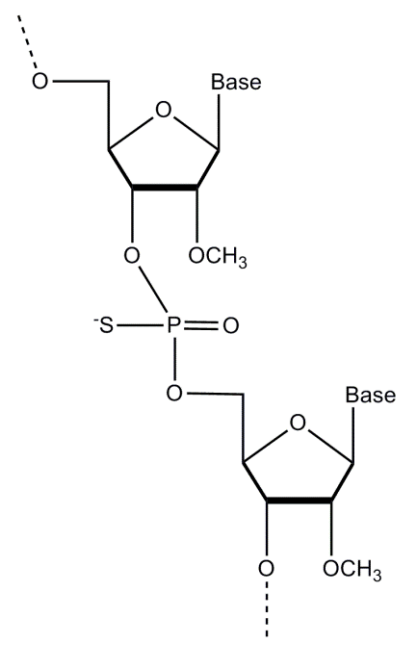

D. PS Backbone Modification

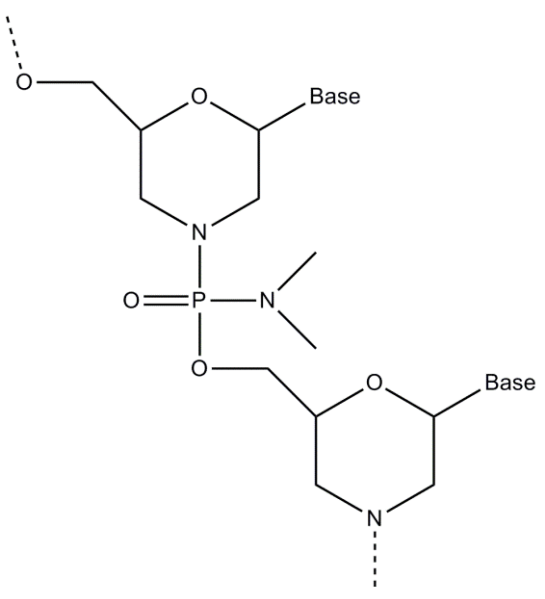

F. PMO

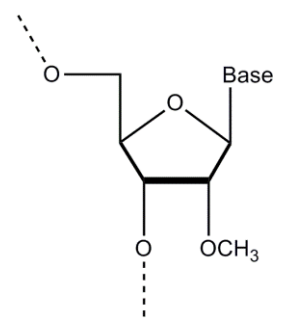

B. OMe

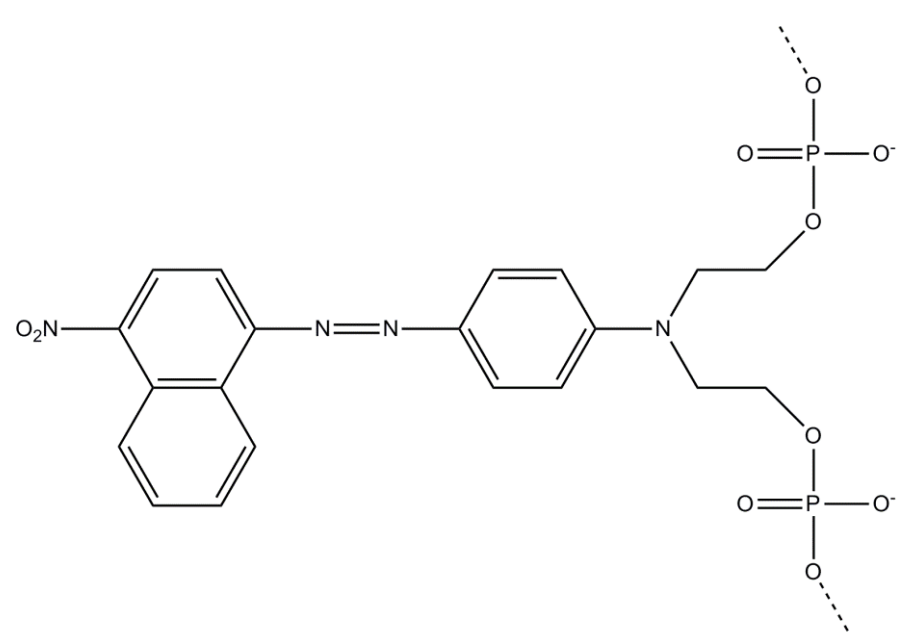

E. ZEN Backbone Modification

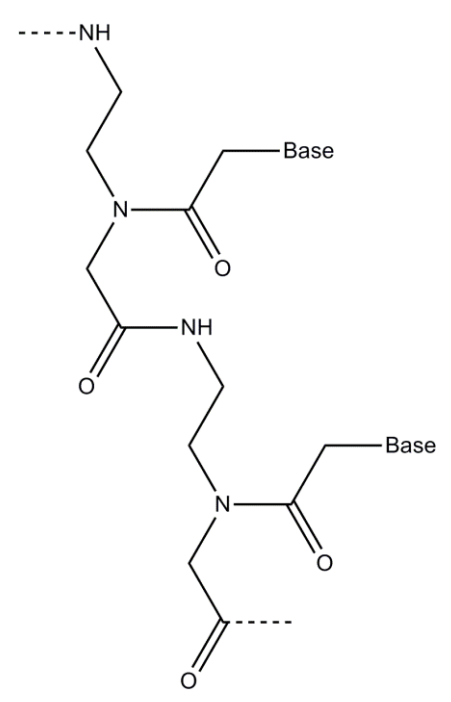

G. PNA

Figure 2. Common oligonucleotide modifications to improve anti-miR activity. (A) The 2 ' $\mathrm{OH}$ of ribose RNA can be methylated to create (B) OMe-modified RNA, or a methylene bridge can be added between the ribose 2'-O and 4'-C to create (C) locked nucleic acid (LNA). (D) The 
phosphodiester bonds in the backbone can be replaced with phosphorothiolate (PS) bonds, or a (E) ZEN modifier can be added between phosphate groups near oligo ends. Finally, neutrallycharged, synthetic (F) phosphorodiamidate morpholino oligonucleotide (PMO) and (G) peptide nucleic acid (PNA) chemistries can also be designed strongly inhibit miRNA.

A recent, alternative approach to improve DNA-based AMO activity without modifying basic nucleic acid chemistry is to design DNA that "puts a lid on miRNA." Known as LiDNA, these structures contain two single-stranded miRNA binding regions between two double-stranded DNA segments [45]. LiDNA are thought to bind miRNA with higher affinity than typical single stranded DNA AMOs by reducing the free motion of the middle miRNA binding region [45]. When delivered in vitro using a cationic liposomal transfection reagent, LiDNA targeting miR-16 showed inhibitory activity at doses as low as $10 \mathrm{nM}$, and the inhibition effect of LidNA-16 was sustained for five days [46]. However, to our knowledge, there have not yet been any direct comparisons made between the miRNA binding affinity and nuclease stability of LiDNA and the other AMOs discussed in this section.

\section{2 miRNA sponges}

In contrast to AMOs, which act transiently to inhibit miRNA, miRNA sponges are long RNA transcripts expressed from transgenes transfected into cells that allow for longer term miRNA inhibition [47]. Synthetic miRNA sponges are analogous to the recently elucidated member of the transcriptome known as competing endogenous RNA (ceRNA) [48-49]. The ceRNA function as competitive inhibitors that bind to miRNAs and block interactions with mRNA. A very recent study has also hypothesized the existence of circular RNA (circRNA), which contain up to 70 miRNA competitive binding sites and act as ceRNAs [50]. Expression of miRNA sponges mimics ceRNA by "soaking up" miRNA and limiting its access to RISC loading and downstream 
target mRNA (Figure 1D). Although miRNA sponges are nucleic acid based inhibitors of miRNA, they differ from AMOs in that they are expressed from transgenes within target cells and may contain one or multiple competitive miRNA binding sites [51-52]. Ebert, Neilson, and Sharp demonstrated that active miRNA RISC complexes bind to miRNA sponges containing binding sites complementary to the target miRNA, thus sterically preventing miRNA binding to and cleaving of natural mRNA targets [52]. In in vitro luciferase studies, an anti-miR-20 sponge outperformed both LNA and OMe AMOs, at a $20 \mathrm{nM}$ dose for up to 48 hrs. The authors note, however, that high levels of miRNA inhibition occur only when the miRNA sponge plasmids contain strong promoters or when multiple vector copies are transfected into the cells [52].

The miRNA sponges can also be designed to be more potent miRNA inhibitors by using "bulged" sequences that are imperfectly complementary to the miRNA and thus less prone to RISC-mediated degradation $[47,52]$. Another modification reported to enhance sponge anti-miR activity is to increase the number of miRNA binding sites on a single sponge, although this effect eventually saturates $[47,52]$. A variety of modified miRNA sponge architectures have been developed including the miRNA eraser, miRNA mower, tough decoy (TuD), and LidNA [51]. These modifications include targeting multiple miRNAs on a single sponge [53], and extending the miRNA inhibition timeframe by getting more stable transduction using lentiviral vectors [54].

An advantage of using a miRNA sponge or decoy approach for regenerative medicine is that they can be continually expressed within transfected/transduced cells and thus can more stably reprogram cells treated in vitro prior to subsequent use in regenerative applications in vivo [51]. Several groups have delivered anti-miRs to cells ex vivo in order to study loss of function phenotype of the cells implanted in vivo [55-57]. For example, Papapetrou, Korkola, and Sadelain used a lentivirus to transfect bone marrow cells with a vector expressing anti-miR sponge target sequences for miRNA-144 and miR-451 [56]. These cells were then transplanted into irradiated mouse bone marrow to probe the functions of miR-144 and miR-451 in the 
murine hematopoietic system. Three to four weeks after bone marrow transplantation, hematopoietic cells harboring lentivirally-encoded anti-miRs gave rise to $\sim 15 \%$ less erythroid cells than those transfected with a control vector. Although the main goal of this loss-of function study was to demonstrate that the miR-144/451 locus is essential to mammalian erythropoiesis [56], it also demonstrates the feasibility of using ex vivo viral miRNA sponge transfection to reprogram cells prior to transplantation in vivo. Other studies have shown that viral vectors can be used to deliver miRNA sponge constructs to target tissue in vivo [58]. While viral delivery of miRNA sponges may be the ideal inhibitors for chronic diseases such as diabetes (where stable miRNA inhibition is preferred), regenerative applications, such as those concerned with tissue development or repair, may be ideally approached using anti-miRs that achieve transient miRNA inhibition [59].

\subsection{Small molecule inhibitors}

The need for potent miRNA inhibitors with improved pharmacokinetics has motivated development of non-nucleic acid-based small molecule miRNA inhibitors. Small molecule inhibitors circumvent some of the drug delivery challenges that can limit in vivo use of AMOs and miRNA sponges, including cell uptake, nuclease-based degradation, and recognition by the innate immune system [60]. In addition, small molecule drugs fit better into the classical drug development process established within larger pharmaceutical companies. Thus, small molecules are generally considered to be easier to deliver and less expensive to manufacture than nucleic acid-based therapeutics.

Several small molecules have been discovered that can inhibit the miRNA pathway [61]. Some of these molecules, such as substituted dihydropteridinone ATP analogues, are general inhibitors of miRNA pathways and act by preventing formation of active RISC complexes (Figure 1F) [62]. Others, such as the diazobenzene discovered by Dieters et al., suppresses the activity of miR-21, they hypothesize, by preventing the transcription of the miR-21 gene into pri-miRNA 
(Figure $1 \mathrm{H}$ ) [63]. The approach in the Dieters group is to develop cell assays that serve as a readout for miR inhibition and then utilize this tool to screen small molecule libraries to uncover miR inhibitors [64]. Other non-cell based screening approaches include assessing binding affinity for mature miRNAs, as has been described for inhibitors such as helix-threading peptides $[61,65]$.

Though small molecules have some advantageous drug properties, small molecule antimiRs typically have decreased specificity for miRNA targets and therefore have a higher potential for side effects compared to nucleic acid-based inhibitors [66]. In an attempt to mitigate the potential for off-target effects, high throughput screening (HTS) approaches have been devised to simultaneously test both the anti-miRNA activity and toxicity of each small molecule within a library of compounds [61,67]. Identifying and testing for the complex outcomes typically desired in regenerative medicine is difficult to replicate in a cellular assay compatible with HTS, and it is therefore a formidable challenge to screen small molecule libraries for "hits"[61, 68-69]. Furthermore, molecules identified by in vitro high throughput screening often have poor solubility or cause adverse, off-target effects not identified by HTS once applied in vivo [70]. Therefore, there is an ongoing challenge to develop improved screening methods to find small molecule inhibitors of specific miRNAs.

\section{Delivery considerations for anti-miR therapies}

Regenerative medicine brings a unique set of anti-miR delivery considerations and challenges. Plasmid- and oligonucleotide-based anti-miR therapies must overcome conventional nucleic acid delivery barriers including nuclease degradation, cell membrane impermeability, trafficking to the desired intracellular compartment (nucleus for plasmid, cytosol for AMOs), and generally transient activity. Small molecule based therapies are still relatively uncharacterized for offtarget effects and specificity. Anti-miR delivery approaches vary based on the class of inhibitor, 
the delivery route, and the target tissue. For example, in dispersed diseases like atherosclerosis, or for tissue targets that are difficult to access by direct injection, systemic antimiR delivery approaches may be preferred [58]. For local applications in poorly vascularized tissue, such as meniscus and cartilage repair, direct tissue injection of anti-miR or controlled release anti-miR depots may be optimal. One possible anti-miR delivery approach is to use a scaffold and/or hydrogel that simultaneously serves as a tissue template and allows for local and sustained anti-miR release [71]. Another strategy that is relatively unique to tissue engineering is anti-miR delivery to cells prior to implant or during transplant to either direct cell differentiation or enhance subsequent cell survival [56]. While end application does necessitate obvious differences in therapeutic strategy, all anti-miR delivery approaches share the need to achieve efficient biodistribution to the target tissue site / cell type, cellular internalization, and intracellular trafficking to the site of action, typically to the cytosol where mature miRNA and the RISC machinery are located. The previous section discusses approaches to modify the drug molecule chemistry, especially of AMOs, to enhance their pharmaceutical properties, while this section will discuss delivery technologies that have been applied to address these delivery barriers.

\subsection{Non-viral delivery}

Basic scientists often carry out in vitro mechanistic studies utilizing non-viral delivery methods and reagents (e.g., cationic lipofection reagents) that are not suitable for clinical use [72-75]. However, a variety of agents have been developed with the intent to improve clinical anti-miR delivery and to expand the therapeutic index of anti-miRs. Examples of these agents include dendritic polymer nanoparticles [76], amphiphillic polymer micelles [77], gold nanoparticles [78-79], porous silicon nanoparticles [80], lipid nanoparticles [37, 81-82], and cell penetrating peptides (CPPs) [37, 83]. While CPPs conjugated directly to AMOs to increase oligo intracellular delivery, CPPs can also be attached to the surface nanoparticles to improve uptake 
of AMO-carrying nanoparticles into cells and tissues. For instance, Cheng and Saltzman demonstrated that addition of the CPP nona-arginine to the surface of their AMO-loaded poly(lactic-co-glycolic acid) (PLGA) polymer nanoparticles significantly increased uptake in human KB oral carcinoma cells relative to unmodified nanoparticles [84].

Of these non-viral vectors, nanoparticles and liposomes in particular have been pursued for systemic anti-miR delivery applications, notably for liver targeting [81, 85], and tumor targeting $[36,86]$. For example, intravenous injection of lactosylated gramicidin-containing lipid nanoparticles (Lac-GLN) loaded with OMe-modified anti-miR-155 AMOs (1.5 mg/kg AMO dose) resulted in anti-miR-155 accumulation in the liver and a 6.9- and 2.1-fold respective increases in anti-miR-155 target genes CCAAT-enhancer binding protein beta (C/EBP $\beta)$ and forkhead box P3 (FOXP3), 48 hours after injection. Although the miRNA in this study, miR-155, was targeted for its oncogenic role in hepatocellular carcinoma, these results suggest that Lac-GLN can be applied as a liver-specific delivery vehicles for anti-miR therapy [81]. Other anti-miR delivery vectors demonstrated to target the liver in vivo are interfering nanoparticles (iNOPs), which are lysine-containing, dendritic nanoparticles decorated with lipid chains [76]. In mice, intravenous delivery of iNOPs complexed with RNA-based anti-miR-122 (at a $2 \mathrm{mg} / \mathrm{kg}$ dose) resulted in a $83.2 \pm 3.2 \%$ decrease in liver-specific miR-122 levels. Although targeting of nanoparticles to tumors is typically more challenging than to liver, there has been some promising work focused on targeting endothelial cells to prevent tumor neovascularization. For example, when coupled to an integrin- $\alpha v \beta 3$ targeting ligand, PEGylated LPH (liposome-polycation-hyaluronic acid) nanoparticles have demonstrated delivery of anti-angiogenic AMOs to tumor vasculature in mice [86]. Conveniently, many of the advances which have been made in improving biodistribution and uptake for plasmids and siRNA (such as shielding with PEG to improve circulation time, or conjugation to targeting antibodies) can be easily adapted for delivery of most AMOs in the context of regenerative medicine [87]. PNA and PMO by exception require additional delivery- 
vector design considerations due to their lack of charge. For example, we previously demonstrated that porous silicon nanoparticles loaded with PNA by in situ synthesis improve intracellular uptake and anti-miR activity of these neutrally-charged AMOs [80].

In contrast to nucleic-acid based anti-miRs, small molecule inhibitors are often delivered systemically without the aid of a carrier. This is in part due to their greater enzymatic stability and cell membrane permeability. Even so, systemic delivery of small molecules requires repeated dosing to maintain a therapeutic but non-toxic concentration, and high biodistribution to the liver and kidneys can limit the dose. One potential strategy to optimize the local effects of small molecule miRNA inhibitors at the target site is to incorporate them into biomaterial scaffolds or other depots for local and sustained delivery [88-90]. However, local delivery of small molecules from a biomaterial scaffold may result in rapid diffusional loss of the drug away from the site of interest due to high diffusivity and permeability. More advanced material approaches such as electrospinning techniques that enable encapsulation of drugs into coresheath nanofiber scaffolds may limit this initial burst release [88].

\subsection{Viral delivery}

Viral transduction of target cells is a viable approach for regenerative applications where chronic, degenerative diseases (e.g. osteoarthritis) may benefit from stable expression of miRNA sponges. Viral transduction is well established in delivering transgenes to a variety of tissues when delivered both locally and systemically. Once inside the tissue, viruses need to be delivered to the nucleus where they can express their transgenic miRNA sponges. To ensure that miRNA sponges expressed in the nucleus are then transported to their cytosolic site of action, sponge sequences can be modified via addition of a nuclear export signal, such as a 3' poly(A) tail [91]. Several viral vectors with diverse properties are available for use [92-94]. Adenoviral vectors are commonly-used because they can efficiently achieve high viral titers in 
dividing and nondividing cells, but they suffer from significant immunogenicity and toxicity [95]. Adeno-associated viruses (AAV) have a low risk of disrupting native genes, are stable in the nucleus, and can maintain high levels of gene expression for months or years. AAV are, however, only able to package small transgene cassettes (up to $4.7 \mathrm{~kb}$ ), complex to prepare recombinantly, and comprised of AAV viral capsid proteins that can be immunogenic [96]. Retroviral and lentiviral vectors can package larger transgene casettes $(8-10 \mathrm{~kb})$ and can be used to stably integrate genes into the genomes of a wide variety of cell types for long-term transgene expression, but they are unstable in storage and unable to achieve high viral titers [97]. Of these, adenovirus, lentivirus, and adeno associated virus (AAV) have been used to transduce cells and provide long-term expression of miRNA inhibitors [98-101], and new, safer viral variants are may aid in clinical translation of this delivery technology [102]. Lentiviruses and rAAV have been utilized to achieve stable expression of miRNA inhibiting sponges or tough decoys for loss of function miRNA studies [100, 103]. For example, intravenous injection of rAAV encoding an anti-miR122 sponge reduced serum cholesterol in mice by $>30 \%$ for 25 weeks [100], consistent with previous studies which have shown that miR-122 plays a critical role in regulating cholesterol biosynthesis [31].

In spite of these promising demonstrations of viral-mediated miRNA inhibition, achieving biodistribution to the target tissue, cell tropism, and viral immunogenicity remain concerns [104]. One potential approach for improving the activity of virally delivered anti-miRs in certain cell types is through careful design and selection of the promoter. While the powerful cytomegalovirus (CMV) promoter is often used for mammalian cell applications, tissue-specific promoters, such as the prostate-specific probasin promoter [105], may replace the CMV promoter to impart more cell type specificity. Other challenges to clinical translation of viral antimiRs include innate immunity to the DNA or the viral vector [106]. To address these concerns, techniques such as directed evolution and high-throughput screening of large mutant capsid 
libraries are being used to discover viral vectors that avoid immune detection and have preferential affinity to specific tissue and cell types [107-108]. A final issue which needs to be addressed is the potential for insertional mutagenesis, which is a concern with some viral vectors, specifically lentivirus [109].

\subsection{Scaffold-mediated delivery}

For regenerative applications, local application bypasses many of the systemic delivery barriers by directly increasing the dose in the target tissue relative to off-target sites. An added benefit is that anti-miR approaches may be integrated with conventional regenerative biomaterial scaffolds that can simultaneously create tissue templates and provide platforms for sustained/controlled release, enabling greater spatiotemporal control over miRNA activity. The materials engineered to deliver anti-miRNA molecules or nucleic acids would be analogous to the technologies used for the delivery of plasmid [110-111] and siRNA [71, 112-113] as reparative/regenerative therapies. Local anti-miR delivery strategies may also be enhanced through substrate mediated transfection achieved by material surface immobilizing or anti-miRs [114-116]. Material mediated viral delivery has also been use to enhance local delivery and confine cell transduction within specific tissues [117]. Such local delivery strategies may be critical in minimizing off-target effects, as the promiscuous nature of miRNAs makes the side effects of long term inhibition difficult to predict. 


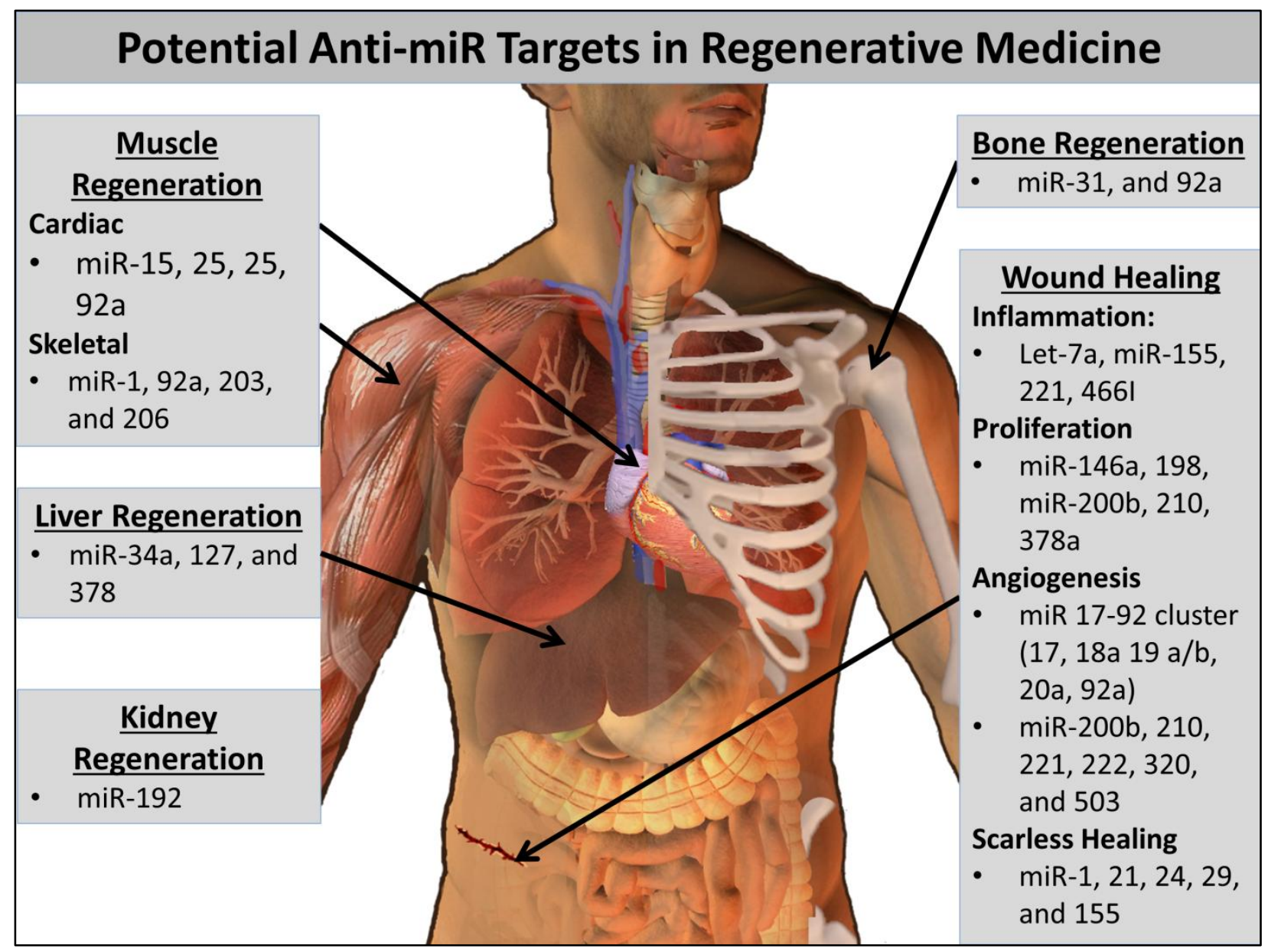

Figure 3. Potential anti-miR targets for regenerative medicine.

\section{Regenerative medicine targets}

Basic scientists have and continue to elucidate a plethora of miRNAs and their mRNA targets. These discoveries provide abundant new opportunities for development of interventions to enhance tissue regeneration (Figure 3). Anti-miRs may prove to be important both for development of translatable therapeutics and for mechanistic, loss-of-function studies intended to better understand miRNA function in tissue development and healing. Both the potential advantage and the potential downfall of targeting miRNAs in tissue regeneration is the robust, and often incompletely understood, effects that miRNAs can have on networks of multiple genes. It is, however, enticing that a single therapeutic could orchestrate a more comprehensive 
response that better recapitulates the complex biological control of tissue regeneration. In this section, we will review the foundational work on therapeutic applications of anti-miRs and also highlight some potentially promising targets that have not yet been therapeutically tested in vivo. Where possible, we have correlated functional therapeutic outcomes with the associated \% miRNA inhibition determined by quantitative-polymerase chain reaction (qPCR) and/or northern blotting. It is important to note, however, that there are potential artifacts associated with using these methods to measure active intracellular miRNA levels [118]. PCR quantification of downstream genes that are regulated by the targeted miRNA, miRNA reporter methods (such as luciferase under the control of miRNA target sites), and/or measurement of the miRNA level following Argonaute immunoprecipitation may more accurately quantify the active miRNA pool within cells [118].

\subsection{Bone regeneration}

The current clinical gold standards for healing of critical-sized defects (CSDs), defined as bone defects that do not spontaneously heal over the life-time of the animal, are osteoconductive and osteoinductive autografts. These approaches, however, are often limited by infection, pain, donor sire morbidity, loss of function, and limited supply [119]. Bone tissue engineering has shown tremendous promise as a more effective approach for healing bone CSDs [120-123]. Bone regeneration can be improved through use of tissue scaffolds and/or the delivery of proteins or other therapeutics that stimulate osteogenesis and angiogenesis, such as factors that stimulate expression of bone morphogenic proteins (BMPs) [124], vascular endothelial

growth factor (VEGF), and hypoxia-inducible factor-1a (HIF-1a) [125-130]. As a potentially advantageous alternative to delivery of a single protein, the endogenous expression of multiple growth factors can be simultaneously regulated by overexpression or inhibition of miRNAs [131]. Consequently, modulation of specific miRNA might allow for optimized bone regeneration through optimal coordination of angiogenesis and osteogenesis processes [132]. In one recent 
example, it was discovered that miR-92a was down-regulated in human patients in response to trochanteric fractures [133]. MiR-92a targets integrin alpha-5 and mitogen-activated protein kinase 4 , and is thought to be an inhibitor of angiogenesis [11, 134]. To determine whether down-regulation of miR-92a helps to promote fracture healing and to test whether systemic down-regulation of miR-92a can enhance the endogenous fracture repair process, LNA targeting miR-92a were administered to mice given femoral fractures. Both repeated systemic delivery of anti-miR-92a by tail vein injections and repeated local delivery by direct injection significantly enhanced fracture healing and neovascularization [133].

In addition to coordinating angiogenesis, miRNA inhibition may provide a powerful tool for enhancing mesenchymal stem cell (MSC) function in tissue engineered constructs [132, 135]. For example, inhibiting endogenous miR-31 significantly increases the osteogenic potential of bone mesenchymal stem cells (BMSCs) [136]. In one demonstration, Deng et al. lentivirallytransfected BMSCs to express anti-miR-31 and observed a 2.5-fold increase in expression of special AT-rich sequence-binding protein 2, a protein involved in osteoblastic differentiation and bone development [137]. This increased expression was maintained in vitro at a relatively constant level between 4 and 21 days after treatment [137]. To determine whether modulation of miR-31 activity in BMSCs affected CSD repair in vivo, BMSCs were transfected in vitro with anti-miR-31 containing vectors, seeded 24 hours later onto poly(glycerol sebacate) (PGS) scaffolds, and then implanted into $8 \mathrm{~mm}$ rat calvarial CSDs. Eight weeks after surgery, microCT was used to visualize the amount of bone ingrowth into the defects (Figure 4). Overall, incorporation of cells pre-treated with anti-miR-31 into the PGS scaffold significantly increased bone regeneration in a CSD when compared with the PGS alone [137], demonstrating that bone tissue engineered constructs can improve tissue integration and regeneration through incorporation of anti-miR therapeutics. 
a
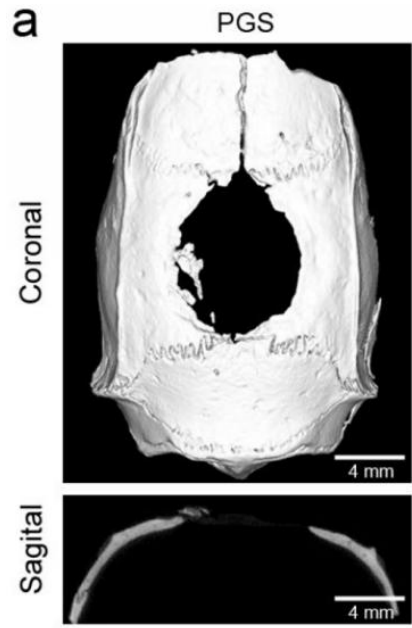

miR-Neg
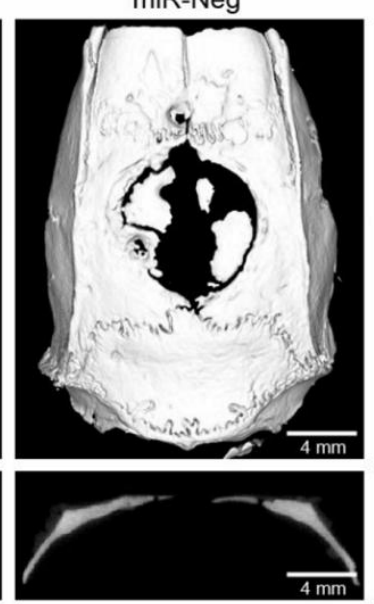

$\operatorname{miR}-31$

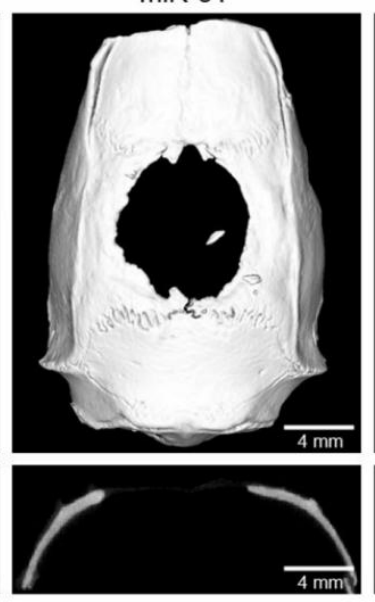

anti-miR

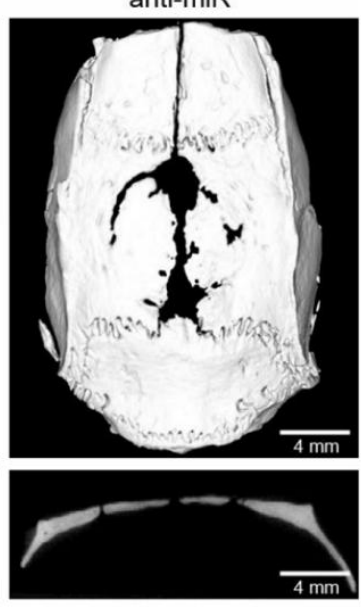

Figure 4. Micro-CT sections following implantation of PGS scaffolds without BMSCs (PGS), or seeded with BMSCs transfected with lentiviruses encoding for miR-31 overexpression (BMSCs/miR-31), miR-31 inhibition (BMSCs/anti-miR), or an irrelevant DNA sequence (BMSCs/miR-Neg). These data suggest that miR-31 impairs bone repair, while transfection of BMSCs with anti-miR-31 prior to implantation greatly increases bone regeneration. Reproduced with kind permission from eCM journal (www.ecmjournal.org).

\subsection{Liver regeneration}

Human liver tissue, unlike cardiac muscle and cartilage, has tremendous ability to regenerate and can regulate both its growth and mass [138]. For example, successful regeneration has been shown following removal of approximately $70 \%$ of the liver in rat studies [139]. This regenerative capacity is primarily due to the ability of hepatocytes to adapt to variable metabolic demands and proliferate to repopulate the liver in response to tissue damage or resection [138]. In the event that hepatocyte proliferation is impaired by injury, as is the case in massive necrosis and carcinogenesis, the liver also possesses stem-like precursor cells capable of differentiating into mature hepatocytes [138]. Despite the endogenous repair capabilities of the liver, 17,000 adults and children with chronic liver disease were medically approved for liver 
transplants in 2013 , and every year, more than 1,500 people die waiting for a donated liver to become available [140]. While anti-miR therapies are relatively unexplored in this context, the need for a better alternative to liver transplants motivates research on miRNA targets that may be relevant for liver regeneration in vivo.

Many studies have shown that miRNA are key regulators of hepatic regeneration process, including miR-378, 127, and 34a Transgenic mouse knock-out studies revealed that downregulation of miR-378 promotes DNA synthesis in the early phase of liver regeneration by increasing the expression of the miR-378 target ornithine decarboxylase [141]. Decreased miR127 levels have been correlated with significant up-regulation of Bcl6 and Setd8 target genes, and increased hepatocyte proliferation [142-144]. In another study, it was shown that upregulation of miR-34a suppresses hepatocyte proliferation via inhibition of inhibin $\beta B$ [145]. Taken together, these studies help to identify promising anti-miR targets that may therapeutically promote hepatocyte proliferation and restoration of proper liver architecture.

\subsection{Kidney regeneration}

In response to acute injury, mammalian kidneys can undergo significant remodeling and cellular repair through mitosis and proliferation of neighboring cells [146]. The cells responsible for kidney repair are thought to be derived from interstitial cell transdifferentiation [147], dedifferentiation of renal cells followed by migration to the damage site and redifferentiation [148-149], or migration of BMSCs to the damaged tissue [150-151]. In situ regenerative medicine strategies which encourage the recruitment of stem cells to the kidney or the dedifferentiation of resident renal cells may therefore be attractive approaches for repairing acute tissue damage [146]. For example, pro-angiogenic miRNAs released from endothelial progenitor cells following renal ischemia-reperfusion injury can have paracrine effects to reprogram resident tubular cells within the hypoxic environment to adopt a regenerative 
phenotype [152]. Consequently, there may be therapeutic potential in reprogramming of renal cells by delivery of anti-miRs to inhibit anti-angiogenic or anti-proliferative miRNAs. An alternative possibility could be to culture stem cells ex vivo for reprogramming and deliver them to damaged kidneys [146].

In chronic injury, the kidney responds with fibrosis, scarring, and irreversible loss-offunction [146]. Diabetic nephropathy (DN) is a chronic, incurable disease that is the most common cause of total renal failure [153]. DN is characterized by thickening of the glomerular basement-membrane, mesangial expansion and hypertrophy, and extracellular matrix protein accumulation [154]. Already, many studies have highlighted the promise of miRNAs both as biomarkers and therapeutic targets for chronic renal disease [153, 155-157]. A 2007 study identified miR-192 as a potential target for inhibition in order to decrease the collagen accumulation associated with DN fibrosis [153]. Repeated subcutaneous injections of LNA anti$\mathrm{miR}-192$ in diabetic mice $(2 \mathrm{mg} / \mathrm{kg}$ twice a week up to 4 weeks, and then subsequently once weekly until sacrifice at 17 weeks) decreased miR-192 levels by $\sim 60 \%$ over the course of 17 weeks, resulting in $~ 3$ - and 1.5-fold increased expression of the E-box repressors Zeb1/2 in the renal glomeruli and cortex, respectively. In addition, the mRNA levels of the pro-fibrotic genes regulated by Zeb1/2 (TGF $\beta$, fibronectin, and collagen) were significantly decreased in the renal cortex for up to 12 weeks, and decreased in the glomeruli for up to 17 weeks [158]. Histological comparison of kidney sections taken from non-diabetic, diabetic control, and diabetic mice treated with LNA anti-miR192 indicate that LNA anti-miR significantly attenuates both glomeruli growth and mesangial cell expansion that characterizes diabetic pathology (Figure 5). This study demonstrates the promise of anti-miR delivery to the kidneys as a strategy for in situ recovery of tissue function in chronic kidney disease. 


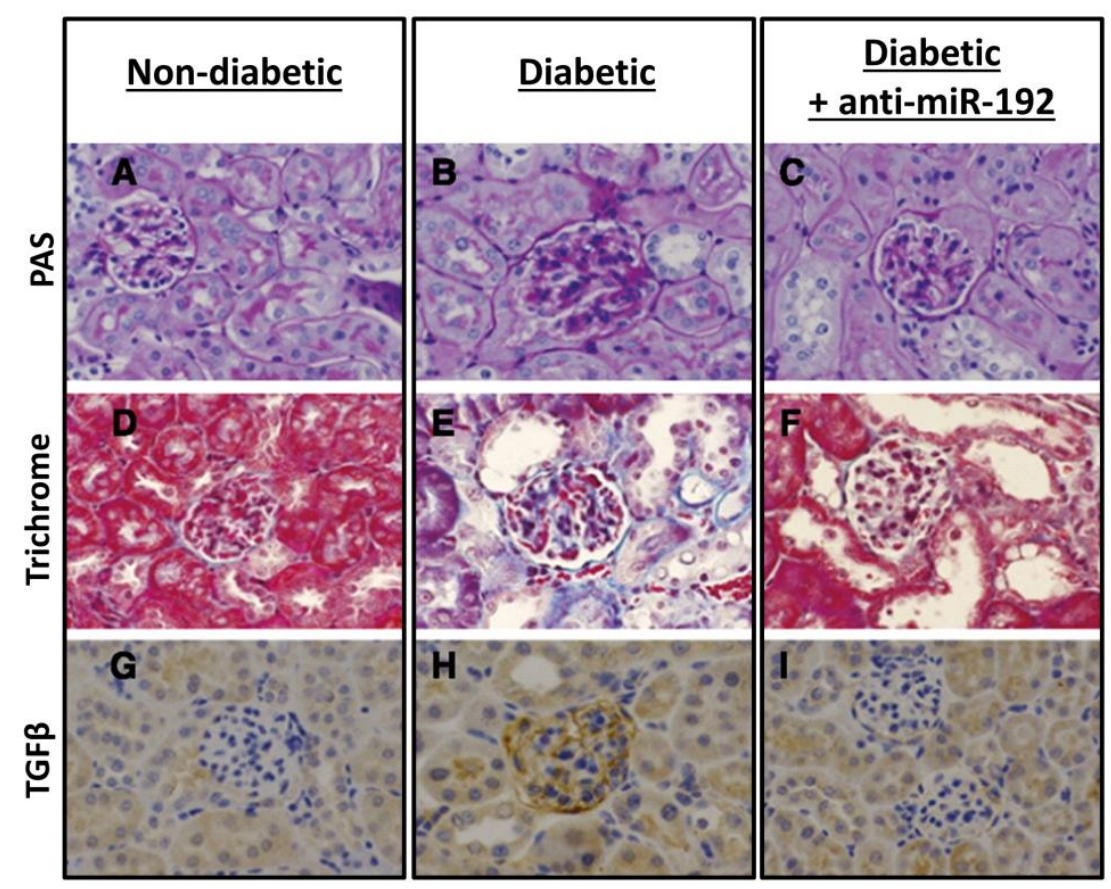

Figure 5. LNA-anti-miR-192 attenuates glomerular growth, mesangial expansion, and TGF $\beta$ expression in 17-week diabetic mice. (A-C) Periodic acid-Schiff [PAS] staining of representative kidney sections. (D-F) Masson's trichrome staining showing glomerular and tubulointerstitial fibrosis. (G-I) TGF- $\beta$ immunostaining of kidney sections. Reproduced from Putta et al. (2012); with kind permission of the Journal of the American Society of Nephrology.

\subsection{Muscle regeneration}

5.4.1 Skeletal muscle regeneration. Several miRNAs are integral in the development of skeletal and cardiac muscle and regulating the regenerative potential of muscle progenitors. Muscle related miRNAs (termed myomiRs) such as miR-1, miR-206, and miR-133 play an integral role in guiding muscle differentiation [159]. Chen et al. recently examined the role of miRNAs in regenerating skeletal muscle and found miR-1 and miR-206 were significantly down-regulated [6]. These authors demonstrated that inhibition of miR-1 and miR-206 using two antagomir 
injections at a dose of $80 \mathrm{mg} / \mathrm{kg}$ body weight increased paired-box transcription factor 7 (Pax7) levels in vivo, 24 hours after treatment. Pax7 is an indicator of muscle satellite cells, which are a critical cell type in muscle tissue regeneration; satellite cell absence prevents myogenesis following skeletal muscle injury [160-162]. However, other studies have suggested presence of miR-206 improves skeletal muscle regeneration in Duchenne muscular dystrophy [163] and also delays Amyotrophic lateral sclerosis progression [164] suggesting that the roles of myomiRS are highly context dependent and that caution should be exercised in choice of anti-miR therapies [159]. Several other non-myomiRs also play a role in skeletal muscle regeneration. Notably, miR-203 has been shown to inhibit skeletal muscle proliferation and differentiation by inhibiting c-Jun and MEF2C and may be a potential therapeutic target for anti-miRs [165] .

5.4.2 Cardiac muscle regeneration. Cellular and tissue functions relevant to heart failure, including myocardial hypertrophy and infarction, are also regulated by miRNAs. Although the causes of heart failure are diverse, encompassing such diseases as atherosclerosis, hypertension, and myocarditis, the defining characteristic of heart failure is loss of contractile function and reserve [166]. The complex intracellular network that governs cardiomyocyte contractility and intracellular $\mathrm{Ca}^{2+}$ handling presents an intriguing opportunity for therapeutic miRNA inhibition. In this context, Wahlquist et al. recently utilized high-throughput screening to identify miRNAs that functioned to suppress contractility by down-regulating calciumtransporting ATPase SERCA2a [167]. From this screen, miR-25 was identified and confirmed to be up-regulated in human myocardial samples from patients with severe heart failure. The authors then demonstrated that overexpression of miR-25 with an AAV9 vector decreased SERCA2a levels in mouse ventricular myocardia, causing decreased cardiac function (as measured by a decline in fractional shortening). To test the effectiveness of miR-25 as a therapeutic target, mice were subjected to 3 months of trans-aortic constriction (TAC) to model chronic failure. The animals were then treated with repeated intravenous injections of a 
commercial anti-miR-25 AMO (300 $\mu \mathrm{g}$ oligonucleotide per dose delivered by jetPEI into the tail vein consecutively for 3 days, with 3 additional injections performed once a week for the following 3 weeks) [168]. Histological analyses 5.5 months after TAC revealed that $\sim 30 \%$ reduction in miR-25 levels following anti-miR treatment significantly reduced cardiac tissue fibrosis when compared to injection of a scrambled control miRNA (Figure 6), while echocardiographic analysis revealed that anti-miR-25 treatment restored loss of SERCA2a protein and significantly improved left ventricular and overall cardiac function. Further, anti-miR25-treated mice demonstrated stabilized heart to body weight ratios, culminating in an increased survival rate with 7/8 anti-miR-25-injected and 8/8 sham-operated animals surviving compared to $7 / 22$ of the control anti-miRNA-injected animals [168].

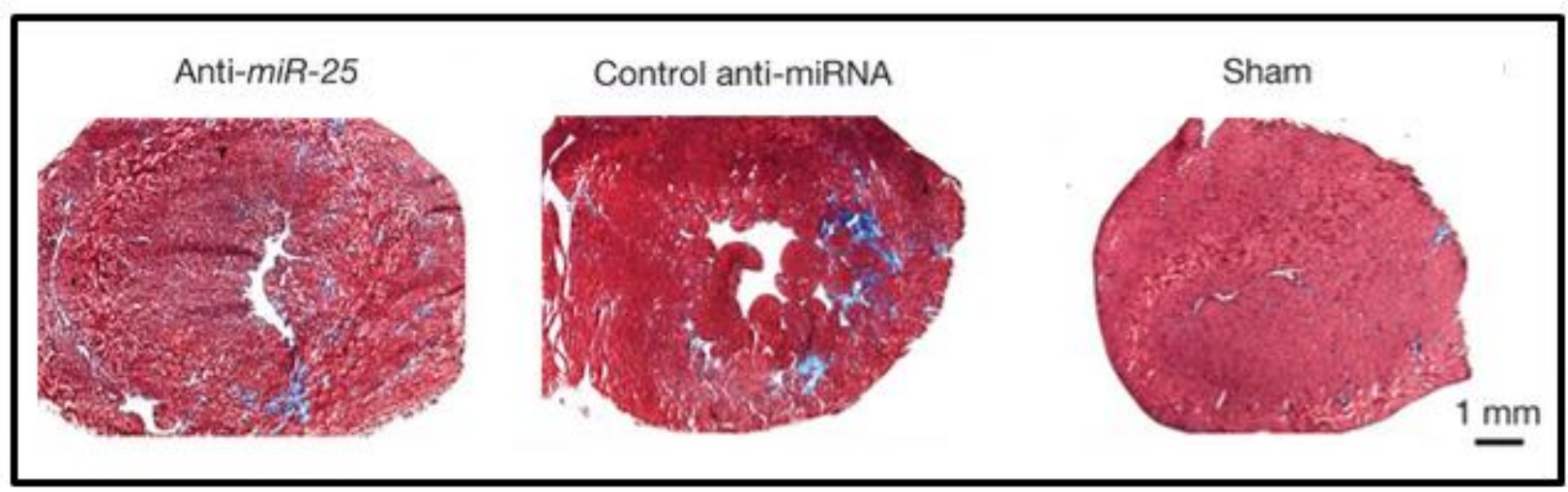

Figure 6. Histology of heart tissue sections stained with Masson's trichrome reveals that inhibition of miR-25 reduces fibrosis under conditions that mimic heart failure. Reproduced and adapted with kind permission from Nature Publishing Group.

While the systemic approach taken by Wahlquist and company is a promising strategy for restoring mycardiocyte contractility following heart failure, it may also be possible to use anti$\mathrm{miR}$ therapies to prevent progression to heart failure in patients following myocardial infarction (MI). For example, local, adenoviral delivery of miR-24 sponges post-MI improved blood perfusion, reduced the infarct size and improved cardiac function [169]. In another example, Bonauer et al. discovered that repeated intravenous injection miR-92a antagomir (8 mg/kg 
injected at days $0,2,4,7$, and 9) decreased miR-92a levels by $\sim 80 \%$ at day 2 in a mouse ischemic limb and by nearly $100 \%$ at day 6 in a mouse heart following acute myocardial infarction (compared to treatment with a scrambled antagomir control). In both models, miR-92a inhibition improved blood vessel growth and functional recovery of damaged tissue [11]. Based on this promising result, Otani et al. used a gelatin hydrogel microsphere (GHM) sheet to deliver miR-92a antagomirs locally to myocardial infarcts in rats [13]. Importantly, they demonstrated that antagomir delivery to the local tissue improved left ventrical remodeling and function (associated with increased angiogenesis in the infarct border, recruitment of stem cells, and cardiomyoctye regeneration) [13]. miR-15 may be another promising target for treating myocardial infarction [14, 170]. Hullinger et al. used LNA anti-miRs to silence the miR-15 family in a mouse model of ischemia-induced myocardial infarction. Intravenous injection with 0.5 $\mathrm{mg} / \mathrm{kg}$ LNA anti-miR-15b at the onset of reperfusion decreased miR-15b levels by $\sim 80 \%$, and reduced infarct size, inhibited cardiac remodeling, and improved heart function [14]. Other miRNAs linked to heart disease, including miR-221 [171], miR-208 [172], miR-21, miR-23a, miR-125, miR-195, miR-199, and miR-214 [173], may also have potential as anti-miR targets, in addition to angiogenic miRNAs such as miR-503 and the miR-17-92 cluster [13, 174-175], which are discussed in more detail in the subsequent section (Angiogenesis).

\subsection{Wound healing}

Wound healing requires coordination of a complex cascade of biochemical events following injury to the skin (or other damaged tissue). These events can be organized into a broader sequence of stages known as coagulation, inflammation, proliferation, angiogenesis, maturation, and remodeling, which are tightly regulated by miRNAs [176-178]. Several miRNAs are known to be preferentially up-regulated or down-regulated during normal wound healing, and miRNA dysregulation may cause pathologic skin conditions and non-healing wounds [174, 179-182]. As successful wound healing will likely necessitate temporal-control over miRNAs, 
this section will review potential miRNA targets as they occur in the different stages of wound healing.

5.5.1 Inflammation. Inflammation is an important early step in wound healing wherein chemokines and cytokines are released to attract phagocytic cells which clean up damaged tissue, bacteria, and other debris from the site of injury before inducing the proliferative phase of healing. If, however, the inflammatory phase is prolonged or excessive, as is often the case for diabetic wounds, inflammation can exacerbate tissue damage and prevent normal wound healing [179, 183-184]. Consequently, miRNAs that either promote or resolve inflammation may be logical targets to improve wound healing [176]. To identify such therapeutically-relevant miRNAs, several studies have examined changes in miRNA profiles in response to inflammation induced in mouse models by injection of lipopolysaccharide (LPS). One such study found miR155 to be up-regulated following LPS injection into the peritoneal space. Up-regulation of miR155 was correlated with increased expression of LPS signaling proteins such as the Fasassociated death domain protein (FADD), IKB kinase $\varepsilon(\mathrm{IKK} \varepsilon)$, and the receptor (TNFR superfamily)-interacting serine-threonine kinase 1 (Ripk1) [185]. In another study, Murphy et al. found that the miRNA let-7a increased inflammation by suppressing NF-kB via destabilization of the inhibitor kB-Ras2 [186]. Both miR-155 and let-7a may, therefore, be promising targets for miRNA inhibitors intended to decrease the excessive inflammation in non-healing wounds. Two other miRNAs involved in the TLR4-mediated immune-response to LPS, miR-221 and miR-466I, have been selected as targets for in vitro studies aimed at decreasing inflammation in microglial cells [187]. In these studies, cell penetrating peptide (CPP)-PEG-PNA constructs targeting miR221 and miR-466l decreased the inflammatory response of microglial cell to LPS stimulation, suggesting miR-221/ -466l inhibition as a potential anti-inflammatory therapy [187]. 
5.5.2 Proliferation. Proliferation, the second phase of wound healing, involves migration and proliferation of endothelial cells and fibroblasts, granulation tissue formation, collagen deposition, and tissue epithelialization by keratinocytes. To increase fibroblast differentiation in mouse skin punch wound model, Li et al. conjugated thiolated anti-miR-378a sponge transcripts onto PEGylated $10 \mathrm{~nm}$ gold nanoparticles. Intradermal administration of anti-miR-378a nanoparticles significantly improved overall wound healing by increasing expression of vimentin and $\beta 3$ integrin, which accelerate fibroblast migration and differentiation [188]. In another approach targeting granulation tissue formation, Feng et al. delivered miR-200b and miR-146a antagomirs topically with lipofectamine (at an antagomir dose of $1.4 \mu \mathrm{g} /$ wound), which decreased local target miRNA levels by $\sim 75 \%$ one day after wounding. This therapy improved healing of cutaneous wounds in normal and diabetic mouse models [189]. In this study, they showed that co-delivery of antagomirs against miR-200b and 146a had a synergistic effect in accelerating wound healing [189]. This work was an extension of previous findings by these authors that an antagomir against miR-146a increased fibronectin production [190] and that an antagomir against miR-200b increased VEGF expression and angiogenesis in the setting of diabetic retinopathy [191].

Inhibition of miRNAs that reduce keratinocyte proliferation is another promising strategy to improve wound healing. Biswas et al. found that miR-210 is driven by ischemia, reduces keratinocyte proliferation, and increases the time to wound closure [192]. They also showed that in vitro delivery of an AMO target to the stem-loop of hsa-miR-210 decreased miR-210 levels by $\sim 80 \%$ and increased keratinocyte proliferation 72 hours after treatment, suggesting its potential as a therapeutic target to improve ischemic wound closure [192]. Similarly, Sundaram et al. recently showed that miR-198 negatively regulates keratinocyte migration to decrease wound healing. Importantly, samples from patients with chronic diabetic ulcers demonstrate differential levels of miR-198, suggesting it may be an effective target to improve wound healing clinically[193]. 
5.5.3 Angiogenesis. Angiogenesis is a critical part of the wound healing process that occurs concurrently with the proliferative phase of wound healing. Failure to generate new and stable blood vessels results in delayed closure. While a number of miRNAs have been demonstrated to be up-regulated and important to improving blood vessel growth [58], others, such as miR221/222, miR-320, and miR-200b, have been identified in vitro as negative regulators of angiogenesis. Induced overexpression of miR-221/miR-222 in transfected cells caused poor tube formation and scratch wound healing [194], while miR-320 is increased in type 2 diabetic Goto-Kakizaki rats and was confirmed as an inhibitor of angiogenesis in myocardial microvascular endothelial cells [195]. The anti-angiogenic function of miR-200b is mechanistically due to negative regulation of VEGF and VEGF receptors [196], and Chan et al. demonstrated that hypoxia-induced miR-200b down-regulation promotes angiogenesis by derepression of v-ets erythroblastosis virus E26 oncogene homolog 1 (Ets-1) [197].

Inhibitors of anti-angiogenic miRNAs that have demonstrated therapeutic promise in vivo include drugs targeting miR-503 and the miR 17-92 cluster [198-199]. MiR-503 is elevated in the plasma and muscles of human diabetics ( 15 fold) and has been implicated in impaired endothelial cell function during angiogenesis [198]. Further, delivery of a miRNA sponge against miR-503 to the ischemic adductor of diabetic mice improved angiogenesis and recovery of blood flow [198]. Likewise, the miR 17-92 cluster (which includes miR-17, 18a ,19a/b, 20a, and 92a) is dysregulated in response to ischemia [199]. Repeated intravenous injections of antagomirs against miR-17 and miR-20 (8 mg/kg injected at days 0,2 , and 4) decreased target miRNA expression by $\sim 80 \%$ and increased angiogenesis on day 7 in subcutaneous matrigel implants in mice [199]. Finally, miR-92a, also discussed above in the context of bone and cardiac regeneration, holds promise as an anti-miR target for promoting angiogenesis [198]. Both direct injection and incorporation into gelatin hydrogel microspheres have proven effective 
for local delivery of LNA and other AMOs against miR-92a to cardiac tissue [13, 200], suggesting that local delivery to a wound site may also be advantageous for promoting wound site angiogenesis and healing.

5.5.4 Scarless healing. Scarring occurs due to repair (rather than regenerative) mechanisms that drive myofibroblast formation and collagen deposition, resulting in fibrosis. A large body of research has been dedicated to 'scarless' healing of wounds and surgical incisions. Pure regeneration occurs during embryonic development but is lost in human adults for all but the most superficial wounds [201]. Consequently, vertebrate animals that maintain this regenerative potential, notably salamanders and zebrafish, are used as models for studies on the roles of miRNA in regeneration. Several miRNAs are promising candidate targets for reducing scarring [202-203], including miR-1, miR-21, miR-24, miR-29, and miR-155 [204]. The primary miRNA evaluated to reduce fibrosis is miR-21, which has been implicated in fibrosis in a number of tissues including lung, heart, kidney, and skin [205-207]. However, local inhibition of miR-21 to reduce fibrosis may delay wound healing, particularly at the early stages of repair [208]. Thus, context and timing of anti-miR delivery will also be key to optimizing clinical outcomes in wound regeneration.

\section{$\underline{6 .}$ Conclusions and clinical outlook}

Modulating miRNA activity provides the ability to achieve greater control over the networks of genes involved in tissue development, homeostasis, and repair and thus motivates research into applications of miRNA inhibition for tissue engineering and regenerative medicine. A large tool box of anti-miR therapies has been developed that target miRNA transcription, miRNA precursors, or mature miRNA in the active RISC complex. Already, studies have used these tools to show that manipulating endogenous miRNAs and/or re-programing cells for implantation 
in tissue-engineered constructs improves regeneration and repair in bone, liver, kidney, and muscle, in addition to improving wound healing.

Potentially the biggest challenge in clinical translation of anti-miR therapies for tissue engineering is achieving efficient biodistribution and activity in the target tissue, such that off target effects are minimized. AMOs, which are the most prevalent and well characterized class of anti-miR therapeutics, suffer from the same delivery barriers that have largely impeded progress of other nucleic acid therapeutics into the clinic. Several companies have taken up this challenge and have begun clinical development of anti-miR therapies, including Santaris Pharma, Regulus Therapeutics, Mirna Therapeutics, and miRagen Therapeutics [209-210]. Regulus Therapeutics has designed anti-miRNAs against miR-21 for myocardial disease and kidney fibrosis [205, 211] and miR-155 for ALS [212]. miRagen Therapeutics is developing an LNA antagonist against miR-208 to treat heart failure by reducing hypertrophy; this strategy has proven effective in diabetic mouse models of diabetes [172, 213-214]. Additionally, miRagen is developing an anti-miR-15 and -195 therapies to improve post myocardial infarction heart regeneration [14, 215]. Ultimately, efforts at increasing our understanding of endogenous miRNA function and our ability to inhibit specific pathological miRNAs may herald a new, more effective generation of regenerative medicines. 


\section{Acknowledgments}

The authors would like to acknowledge support from the National Science Foundation (DMR120701, BMAT 1349604, and Graduate Research Fellowship to KRB) and the National Institutes of Health (NIBIB R21EB012750 and R01EB019409). 


\section{References}

[1] Weiler, J.; Hunziker, J.; Hall, J., Anti-miRNA oligonucleotides (AMOs): ammunition to target miRNAs implicated in human disease? Gene therapy 2005, 13 (6), 496-502.

[2] Davis, M. E.; Zuckerman, J. E.; Choi, C. H.; Seligson, D.; Tolcher, A.; Alabi, C. A.; Yen, Y.; Heidel, J. D.; Ribas, A., Evidence of RNAi in humans from systemically administered siRNA via targeted nanoparticles. Nature 2010, 464 (7291), 1067-70.

[3] Coelho, T.; Adams, D.; Silva, A.; Lozeron, P.; Hawkins, P. N.; Mant, T.; Perez, J.; Chiesa, J.; Warrington, S.; Tranter, E.; Munisamy, M.; Falzone, R.; Harrop, J.; Cehelsky, J.; Bettencourt, B. R.; Geissler, M.; Butler, J. S.; Sehgal, A.; Meyers, R. E.; Chen, Q.; Borland, T.; Hutabarat, R. M.; Clausen, V. A.; Alvarez, R.; Fitzgerald, K.; Gamba-Vitalo, C.; Nochur, S. V.; Vaishnaw, A. K.; Sah, D. W.; Gollob, J. A.; Suhr, O. B., Safety and efficacy of RNAi therapy for transthyretin amyloidosis. N Engl J Med 2013, 369 (9), 819-29.

[4] Graham, M. J.; Lee, R. G.; Bell, T. A., 3rd; Fu, W.; Mullick, A. E.; Alexander, V. J.; Singleton, W.; Viney, N.; Geary, R.; Su, J.; Baker, B. F.; Burkey, J.; Crooke, S. T.; Crooke, R. M., Antisense oligonucleotide inhibition of apolipoprotein C-III reduces plasma triglycerides in rodents, nonhuman primates, and humans. Circ Res 2013, 112 (11), 1479-90.

[5] Tanioka, M.; Nokihara, H.; Yamamoto, N.; Yamada, Y.; Yamada, K.; Goto, Y.; Fujimoto, T.; Sekiguchi, R.; Uenaka, K.; Callies, S.; Tamura, T., Phase I study of LY2181308, an antisense oligonucleotide against survivin, in patients with advanced solid tumors. Cancer Chemother Pharmacol 2011, 68 (2), 505-11.

[6] Chen, J. F.; Tao, Y.; Li, J.; Deng, Z.; Yan, Z.; Xiao, X.; Wang, D. Z., microRNA-1 and microRNA-206 regulate skeletal muscle satellite cell proliferation and differentiation by repressing Pax7. J Cell Biol 2010, 190 (5), 867-79.

[7] Mack, G. S., MicroRNA gets down to business. Nat Biotechnol 2007, 25 (6), 631-8.

[8] Kang, S.; Im, K.; Baek, J.; Yoon, S.; Min, H., Macro and small over micro: macromolecules and small molecules that regulate microRNAs. Chembiochem 2014, 15 (8), 1071-8.

[9] Taibi, F.; Metzinger-Le Meuth, V.; Massy, Z. A.; Metzinger, L., miR-223: An inflammatory oncomiR enters the cardiovascular field. Biochim Biophys Acta 2014, 1842 (7), 1001-9.

[10] Greene, C. M.; Gaughan, K. P., microRNAs in asthma: potential therapeutic targets. Curr Opin Pulm Med 2013, 19 (1), 66-72.

[11] Bonauer, A.; Carmona, G.; Iwasaki, M.; Mione, M.; Koyanagi, M.; Fischer, A.; Burchfield, J.; Fox, H.; Doebele, C.; Ohtani, K.; Chavakis, E.; Potente, M.; Tjwa, M.; Urbich, C.; Zeiher, A. M.; Dimmeler, S., MicroRNA-92a controls angiogenesis and functional recovery of ischemic tissues in mice. Science 2009, 324 (5935), 1710-3.

[12] Weiland, M.; Gao, X. H.; Zhou, L.; Mi, Q. S., Small RNAs have a large impact Circulating microRNAs as biomarkers for human diseases. Rna Biology 2012, 9 (6), 850-859.

[13] Fujita, M.; Otani, H.; Iwasaki, M.; Yoshioka, K.; Shimazu, T.; Shiojima, I.; Tabata, Y., Antagomir-92a Impregnated Gelatin Hydrogel Microsphere Sheet Enhances Cardiac Regeneration after Myocardial Infarction in Rats. Experimental and Clinical Cardiology 2014, 20 (1), 1762-1787.

[14] Hullinger, T. G.; Montgomery, R. L.; Seto, A. G.; Dickinson, B. A.; Semus, H. M.; Lynch, J. M.; Dalby, C. M.; Robinson, K.; Stack, C.; Latimer, P. A.; Hare, J. M.; Olson, E. N.; van Rooij, E., Inhibition of miR15 protects against cardiac ischemic injury. Circ Res 2012, 110 (1), 71-81.

[15] Lanford, R. E.; Hildebrandt-Eriksen, E. S.; Petri, A.; Persson, R.; Lindow, M.; Munk, M. E.; Kauppinen, S.; Orum, H., Therapeutic silencing of microRNA-122 in primates with chronic hepatitis $\mathrm{C}$ virus infection. Science 2010, 327 (5962), 198-201.

[16] Rayner, K. J.; Esau, C. C.; Hussain, F. N.; McDaniel, A. L.; Marshall, S. M.; van Gils, J. M.; Ray, T. D.; Sheedy, F. J.; Goedeke, L.; Liu, X.; Khatsenko, O. G.; Kaimal, V.; Lees, C. J.; Fernandez-Hernando, C.; 
Fisher, E. A.; Temel, R. E.; Moore, K. J., Inhibition of miR-33a/b in non-human primates raises plasma HDL and lowers VLDL triglycerides. Nature 2011, 478 (7369), 404-7.

[17] Janssen, H. L.; Reesink, H. W.; Lawitz, E. J.; Zeuzem, S.; Rodriguez-Torres, M.; Patel, K.; van der Meer, A. J.; Patick, A. K.; Chen, A.; Zhou, Y.; Persson, R.; King, B. D.; Kauppinen, S.; Levin, A. A.; Hodges, M. R., Treatment of HCV infection by targeting microRNA. N Engl J Med 2013, 368 (18), 1685-94.

[18] Palsson, B. O.; Bhatia, S. N., Tissue Engineering. Pearson Prentice Hall: 2004.

[19] Garzon, R.; Marcucci, G.; Croce, C. M., Targeting microRNAs in cancer: rationale, strategies and challenges. Nat Rev Drug Discov 2010, 9 (10), 775-89.

[20] Gregory, R. I.; Chendrimada, T. P.; Cooch, N.; Shiekhattar, R., Human RISC couples microRNA biogenesis and posttranscriptional gene silencing. Cell 2005, 123 (4), 631-40.

[21] Lee, Y. S.; Kim, H. K.; Chung, S.; Kim, K. S.; Dutta, A., Depletion of human micro-RNA miR-125b reveals that it is critical for the proliferation of differentiated cells but not for the down-regulation of putative targets during differentiation. J Biol Chem 2005, 280 (17), 16635-41.

[22] Lennox, K. A.; Behlke, M. A., Chemical modification and design of anti-miRNA oligonucleotides. Gene Ther 2011, 18 (12), 1111-20.

[23] Li, Z.; Rana, T. M., Therapeutic targeting of microRNAs: current status and future challenges. Nat Rev Drug Discov 2014, 13 (8), 622-638.

[24] Kloosterman, W. P.; Lagendijk, A. K.; Ketting, R. F.; Moulton, J. D.; Plasterk, R. H., Targeted inhibition of miRNA maturation with morpholinos reveals a role for miR-375 in pancreatic islet development. PLoS Biol 2007, 5 (8), e203.

[25] Young, J. A.; Ting, K. K.; Li, J.; Moller, T.; Dunn, L.; Lu, Y.; Moses, J.; Prado-Lourenco, L.; Khachigian, L. M.; Ng, M.; Gregory, P. A.; Goodall, G. J.; Tsykin, A.; Lichtenstein, I.; Hahn, C. N.; Tran, N.; Shackel, N.; Kench, J. G.; McCaughan, G.; Vadas, M. A.; Gamble, J. R., Regulation of vascular leak and recovery from ischemic injury by general and VE-cadherin-restricted miRNA antagonists of miR-27. Blood 2013, 122 (16), 2911-9.

[26] Young, J. A.; Ting, K. K.; Li, J.; Moller, T.; Dunn, L.; Lu, Y.; Moses, J.; Prado-Lourenço, L.; Khachigian, L. M.; Ng, M.; Gregory, P. A.; Goodall, G. J.; Tsykin, A.; Lichtenstein, I.; Hahn, C. N.; Tran, N.; Shackel, N.; Kench, J. G.; McCaughan, G.; Vadas, M. A.; Gamble, J. R., Regulation of vascular leak and recovery from ischemic injury by general and VE-cadherin-restricted miRNA antagonists of miR-27. 2013; Vol. 122, p 2911-2919.

[27] Lennox, K. A.; Owczarzy, R.; Thomas, D. M.; Walder, J. A.; Behlke, M. A., Improved Performance of Anti-miRNA Oligonucleotides Using a Novel Non-Nucleotide Modifier. Mol Ther Nucleic Acids 2013, 2, e117.

[28] Boutla, A.; Delidakis, C.; Tabler, M., Developmental defects by antisense-mediated inactivation of micro-RNAs 2 and 13 in Drosophila and the identification of putative target genes. Nucleic Acids Res 2003, 31 (17), 4973-80.

[29] Hutvagner, G.; Simard, M. J.; Mello, C. C.; Zamore, P. D., Sequence-specific inhibition of small RNA function. PLOS Biol 2004, 2 (4), E98.

[30] Lennox, K. A.; Sabel, J. L.; Johnson, M. J.; Moreira, B. G.; Fletcher, C. A.; Rose, S. D.; Behlke, M. A.; Laikhter, A. L.; Walder, J. A.; Dagle, J. M., Characterization of modified antisense oligonucleotides in Xenopus laevis embryos. Oligonucleotides 2006, 16 (1), 26-42.

[31] Krutzfeldt, J.; Rajewsky, N.; Braich, R.; Rajeev, K. G.; Tuschl, T.; Manoharan, M.; Stoffel, M., Silencing of microRNAs in vivo with 'antagomirs'. Nature 2005, 438 (7068), 685-689.

[32] Krutzfeldt, J.; Kuwajima, S.; Braich, R.; Rajeev, K. G.; Pena, J.; Tuschl, T.; Manoharan, M.; Stoffel, M., Specificity, duplex degradation and subcellular localization of antagomirs. Nucleic Acids Res 2007, 35 (9), 2885-92. 
[33] Liu, N.; Bezprozvannaya, S.; Williams, A. H.; Qi, X.; Richardson, J. A.; Bassel-Duby, R.; Olson, E. N., microRNA-133a regulates cardiomyocyte proliferation and suppresses smooth muscle gene expression in the heart. Genes Dev 2008, 22 (23), 3242-54.

[34] Morrisey, E. E., The magic and mystery of miR-21. J Clin Invest 2010, 120 (11), 3817-9.

[35] Patrick, D. M.; Montgomery, R. L.; Qi, X.; Obad, S.; Kauppinen, S.; Hill, J. A.; van Rooij, E.; Olson, E. N., Stress-dependent cardiac remodeling occurs in the absence of microRNA-21 in mice. J Clin Invest 2010, 120 (11), 3912-6.

[36] Obad, S.; dos Santos, C. O.; Petri, A.; Heidenblad, M.; Broom, O.; Ruse, C.; Fu, C.; Lindow, M.; Stenvang, J.; Straarup, E. M.; Hansen, H. F.; Koch, T.; Pappin, D.; Hannon, G. J.; Kauppinen, S., Silencing of microRNA families by seed-targeting tiny LNAs. Nat Genet 2011, 43 (4), 371-8.

[37] Fabani, M. M.; Gait, M. J., miR-122 targeting with LNA/2'-O-methyl oligonucleotide mixmers, peptide nucleic acids (PNA), and PNA-peptide conjugates. RNA 2008, 14 (2), 336-46.

[38] Janson, C.; During, M., Peptide Nucleic Acids, Morpholinos and Related Antisense Biomolecules. Landes Bioscience/Eurekah.com: 2007.

[39] Natsume, T.; Ishikawa, Y.; Dedachi, K.; Tsukamoto, T.; Kurita, N., Hybridization energies of double strands composed of DNA, RNA, PNA and LNA. Chem Phys Lett 2007, 434 (1-3), 133-138.

[40] Nielsen, P. E., Applications of peptide nucleic acids. Curr Opin Biotechnol 1999, 10 (1), 71-5.

[41] Oh, S. Y.; Ju, Y.; Park, H., A highly effective and long-lasting inhibition of miRNAs with PNA-based antisense oligonucleotides. Mol Cells 2009, 28 (4), 341-5.

[42] Ratilainen, T.; Holmen, A.; Tuite, E.; Nielsen, P. E.; Norden, B., Thermodynamics of sequence-specific binding of PNA to DNA. Biochemistry-Us 2000, 39 (26), 7781-91.

[43] Braasch, D. A.; Corey, D. R., Locked nucleic acid (LNA): fine-tuning the recognition of DNA and RNA. Chem Biol 2001, 8 (1), 1-7.

[44] Aartsma-Rus, A.; Kaman, W. E.; Bremmer-Bout, M.; Janson, A. A.; den Dunnen, J. T.; van Ommen, G. J.; van Deutekom, J. C., Comparative analysis of antisense oligonucleotide analogs for targeted DMD exon 46 skipping in muscle cells. Gene Ther 2004, 11 (18), 1391-8.

[45] Ida, H.; Tachibana, A.; Tanabe, T., Binding affinity of ssDNA is improved by attachment of dsDNA regions. Journal of Bioscience and Bioengineering 2014, 118 (3), 239-241.

[46] Tachibana, A.; Yamada, Y.; Ida, H.; Saito, S.; Tanabe, T., LidNA, a novel miRNA inhibitor constructed with unmodified DNA. FEBS Lett 2012, 586 (10), 1529-32.

[47] Tay, F. C.; Lim, J. K.; Zhu, H.; Hin, L. C.; Wang, S., Using artificial microRNA sponges to achieve microRNA loss-of-function in cancer cells. Adv Drug Deliv Rev 2014, (0).

[48] Salmena, L.; Poliseno, L.; Tay, Y.; Kats, L.; Pandolfi, P. P., A< i>ceRNA</i> Hypothesis: The Rosetta Stone of a Hidden RNA Language? Cell 2011, 146 (3), 353-358.

[49] Poliseno, L.; Salmena, L.; Zhang, J.; Carver, B.; Haveman, W. J.; Pandolfi, P. P., A coding-independent function of gene and pseudogene mRNAs regulates tumour biology. Nature 2010, 465 (7301), 1033-8.

[50] Hansen, T. B.; Jensen, T. I.; Clausen, B. H.; Bramsen, J. B.; Finsen, B.; Damgaard, C. K.; Kjems, J., Natural RNA circles function as efficient microRNA sponges. Nature 2013, 495 (7441), 384-388.

[51] Ebert, M. S.; Sharp, P. A., MicroRNA sponges: progress and possibilities. RNA 2010, 16 (11), 2043-50.

[52] Ebert, M. S.; Neilson, J. R.; Sharp, P. A., MicroRNA sponges: competitive inhibitors of small RNAs in mammalian cells. Nat Methods 2007, 4 (9), 721-6.

[53] Liu, Y.; Han, Y.; Zhang, H.; Nie, L.; Jiang, Z.; Fa, P.; Gui, Y.; Cai, Z., Synthetic miRNA-mowers targeting miR-183-96-182 cluster or miR-210 inhibit growth and migration and induce apoptosis in bladder cancer cells. PLoS One 2012, 7 (12), e52280.

[54] Haraguchi, T.; Ozaki, Y.; Iba, H., Vectors expressing efficient RNA decoys achieve the long-term suppression of specific microRNA activity in mammalian cells. Nucleic Acids Res 2009, 37 (6), e43. 
[55] Starczynowski, D. T.; Kuchenbauer, F.; Argiropoulos, B.; Sung, S.; Morin, R.; Muranyi, A.; Hirst, M.; Hogge, D.; Marra, M.; Wells, R. A.; Buckstein, R.; Lam, W.; Humphries, R. K.; Karsan, A., Identification of miR-145 and miR-146a as mediators of the 5q-syndrome phenotype. Nature Medicine 2010, 16 (1), 49-U84.

[56] Papapetrou, E. P.; Korkola, J. E.; Sadelain, M., A genetic strategy for single and combinatorial analysis of miRNA function in mammalian hematopoietic stem cells. Stem Cells 2010, 28 (2), 28796.

[57] Gentner, B.; Schira, G.; Giustacchini, A.; Amendola, M.; Brown, B. D.; Ponzoni, M.; Naldini, L., Stable knockdown of microRNA in vivo by lentiviral vectors. Nat Methods 2009, 6 (1), 63-6.

[58] Caporali, A.; Emanueli, C., MicroRNA regulation in angiogenesis. Vascul Pharmacol 2011, 55 (4), 79 86.

[59] Rhim, C.; Cheng, C. S.; Kraus, W. E.; Truskey, G. A., Effect of microRNA modulation on bioartificial muscle function. Tissue Eng Part A 2010, 16 (12), 3589-97.

[60] Sakurai, H.; Kawabata, K.; Sakurai, F.; Nakagawa, S.; Mizuguchi, H., Innate immune response induced by gene delivery vectors. Int J Pharm 2008, 354 (1-2), 9-15.

[61] Deiters, A., Small molecule modifiers of the microRNA and RNA interference pathway. AAPS J 2010, 12 (1), 51-60.

[62] Chiu, Y. L.; Dinesh, C. U.; Chu, C. Y.; Ali, A.; Brown, K. M.; Cao, H.; Rana, T. M., Dissecting RNAinterference pathway with small molecules. Chem Biol 2005, 12 (6), 643-8.

[63] Gumireddy, K.; Young, D. D.; Xiong, X.; Hogenesch, J. B.; Huang, Q.; Deiters, A., Small-molecule inhibitors of microrna miR-21 function. Angew Chem Int Ed Eng/ 2008, 47 (39), 7482-4.

[64] Connelly, C.; Deiters, A., Identification of Inhibitors of MicroRNA Function from Small Molecule Screens. In miRNA Maturation, Arenz, C., Ed. Humana Press: 2014; Vol. 1095, pp 147-156.

[65] Gooch, B. D.; Beal, P. A., Recognition of duplex RNA by helix-threading peptides. J Am Chem Soc 2004, 126 (34), 10603-10.

[66] Zhang, S.; Chen, L.; Jung, E. J.; Calin, G. A., Targeting microRNAs with small molecules: Between Dream and Reality. Clinical pharmacology and therapeutics 2010, 87 (6), 754.

[67] Connelly, C. M.; Thomas, M.; Deiters, A., High-throughput luciferase reporter assay for smallmolecule inhibitors of microRNA function. J Biomol Screen 2012, 17 (6), 822-8.

[68] Lu, B.; Atala, A., Small molecules and small molecule drugs in regenerative medicine. Drug Discov Today 2014, 19 (6), 801-8.

[69] Young, D. D.; Connelly, C. M.; Grohmann, C.; Deiters, A., Small molecule modifiers of microRNA miR122 function for the treatment of hepatitis $C$ virus infection and hepatocellular carcinoma. J Am Chem Soc 2010, 132 (23), 7976-81.

[70] Grainger, D. W., Cell-based drug testing; this world is not flat. Adv Drug Deliv Rev 2014, 69-70 (Complete), vii-xi.

[71] Nelson, C. E.; Gupta, M. K.; Adolph, E. J.; Shannon, J. M.; Guelcher, S. A.; Duvall, C. L., Sustained local delivery of siRNA from an injectable scaffold. Biomaterials 2012, 33 (4), 1154-61.

[72] Prosser, H. M.; Koike-Yusa, H.; Cooper, J. D.; Law, F. C.; Bradley, A., A resource of vectors and ES cells for targeted deletion of microRNAs in mice. Nat Biotechnol 2011, 29 (9), 840-5.

[73] Zhu, Q. B.; Sun, W. Y.; Okano, K.; Chen, Y.; Zhang, N.; Maeda, T.; Palczewski, K., Sponge Transgenic Mouse Model Reveals Important Roles for the MicroRNA-183 (miR-183)/96/182 Cluster in Postmitotic Photoreceptors of the Retina. Journal of Biological Chemistry 2011, 286 (36), 3174931760.

[74] Sun, K.; Lai, E. C., Adult-specific functions of animal microRNAs. Nat Rev Genet 2013, 14 (8), 535-48.

[75] Park, C. Y.; Jeker, L. T.; Carver-Moore, K.; Oh, A.; Liu, H. J.; Cameron, R.; Richards, H.; Li, Z.; Adler, D.; Yoshinaga, Y.; Martinez, M.; Nefadov, M.; Abbas, A. K.; Weiss, A.; Lanier, L. L.; de Jong, P. J.; 
Bluestone, J. A.; Srivastava, D.; McManus, M. T., A resource for the conditional ablation of microRNAs in the mouse. Cell Rep 2012, 1 (4), 385-91.

[76] Baigude, H.; McCarroll, J.; Yang, C. S.; Swain, P. M.; Rana, T. M., Design and creation of new nanomaterials for therapeutic RNAi. ACS Chem Biol 2007, 2 (4), 237-41.

[77] Qian, X.; Long, L.; Shi, Z.; Liu, C.; Qiu, M.; Sheng, J.; Pu, P.; Yuan, X.; Ren, Y.; Kang, C., Star-branched amphiphilic PLA-b-PDMAEMA copolymers for co-delivery of miR-21 inhibitor and doxorubicin to treat glioma. Biomaterials 2014, 35 (7), 2322-35.

[78] Kim, J. H.; Yeom, J. H.; Ko, J. J.; Han, M. S.; Lee, K.; Na, S. Y.; Bae, J., Effective delivery of anti-miRNA DNA oligonucleotides by functionalized gold nanoparticles. J Biotechnol 2011, 155 (3), 287-92.

[79] Kim, J. H.; Jang, H. H.; Ryou, S. M.; Kim, S.; Bae, J.; Lee, K.; Han, M. S., A functionalized gold nanoparticles-assisted universal carrier for antisense DNA. Chem Commun (Camb) 2010, 46 (23), 4151-3.

[80] Beavers, K. R.; Mares, J. W.; Swartz, C. M.; Zhao, Y.; Weiss, S. M.; Duvall, C. L., In situ synthesis of peptide nucleic acids in porous silicon for drug delivery and biosensing. Bioconjug Chem 2014, 25 (7), 1192-7.

[81] Zhang, M.; Zhou, X.; Wang, B.; Yung, B. C.; Lee, L. J.; Ghoshal, K.; Lee, R. J., Lactosylated gramicidinbased lipid nanoparticles (Lac-GLN) for targeted delivery of anti-miR-155 to hepatocellular carcinoma. J Control Release 2013, 168 (3), 251-61.

[82] Shi, S. J.; Zhong, Z. R.; Liu, J.; Zhang, Z. R.; Sun, X.; Gong, T., Solid lipid nanoparticles loaded with anti-microRNA oligonucleotides (AMOs) for suppression of microRNA-21 functions in human lung cancer cells. Pharm Res 2012, 29 (1), 97-109.

[83] Oh, S. Y.; Ju, Y.; Kim, S.; Park, H., PNA-based antisense oligonucleotides for micrornas inhibition in the absence of a transfection reagent. Oligonucleotides 2010, 20 (5), 225-30.

[84] Cheng, C. J.; Saltzman, W. M., Polymer nanoparticle-mediated delivery of microRNA inhibition and alternative splicing. Mol Pharm 2012, 9 (5), 1481-8.

[85] Elmen, J.; Lindow, M.; Silahtaroglu, A.; Bak, M.; Christensen, M.; Lind-Thomsen, A.; Hedtjarn, M.; Hansen, J. B.; Hansen, H. F.; Straarup, E. M.; McCullagh, K.; Kearney, P.; Kauppinen, S., Antagonism of microRNA-122 in mice by systemically administered LNA-antimiR leads to up-regulation of a large set of predicted target mRNAs in the liver. Nucleic Acids Res 2008, 36 (4), 1153-62.

[86] Liu, X. Q.; Song, W. J.; Sun, T. M.; Zhang, P. Z.; Wang, J., Targeted delivery of antisense inhibitor of miRNA for antiangiogenesis therapy using cRGD-functionalized nanoparticles. Mol Pharm 2011, 8 (1), 250-9.

[87] Kanasty, R.; Dorkin, J. R.; Vegas, A.; Anderson, D., Delivery materials for siRNA therapeutics. Nat Mater 2013, 12 (11), 967-77.

[88] Carbone, E. J.; Jiang, T.; Nelson, C.; Henry, N.; Lo, K. W., Small molecule delivery through nanofibrous scaffolds for musculoskeletal regenerative engineering. Nanomed 2014, (0).

[89] Kouhi, M.; Morshed, M.; Varshosaz, J.; Fathi, M. H., Poly ( $\varepsilon$-caprolactone) incorporated bioactive glass nanoparticles and simvastatin nanocomposite nanofibers: Preparation, characterization and in vitro drug release for bone regeneration applications. Chemical Engineering Journal 2013, 228 (0), 1057-1065.

[90] Piskin, E.; Isoglu, I. A.; Bolgen, N.; Vargel, I.; Griffiths, S.; Cavusoglu, T.; Korkusuz, P.; Guzel, E.; Cartmell, S., In vivo performance of simvastatin-loaded electrospun spiral-wound polycaprolactone scaffolds in reconstruction of cranial bone defects in the rat model. J Biomed Mater Res A 2009, 90 (4), 1137-51.

[91] Carmody, S. R.; Wente, S. R., mRNA nuclear export at a glance. Journal of cell science 2009, 122 (12), 1933-1937.

[92] Wang, Z.; Zhu, T.; Qiao, C.; Zhou, L.; Wang, B.; Zhang, J.; Chen, C.; Li, J.; Xiao, X., Adeno-associated virus serotype 8 efficiently delivers genes to muscle and heart. Nat Biotechnol 2005, 23 (3), 321-8. 
[93] Chao, H. J.; Liu, Y. B.; Rabinowitz, J.; Li, C. W.; Samulski, R. J.; Walsh, C. E., Several log increase in therapeutic transgene delivery by distinct adeno-associated viral serotype vectors. Molecular Therapy 2000, 2 (6), 619-623.

[94] Mingozzi, F.; High, K. A., Therapeutic in vivo gene transfer for genetic disease using AAV: progress and challenges. Nat Rev Genet 2011, 12 (5), 341-355.

[95] Lin, E.; Nemunaitis, J., Oncolytic viral therapies. Cancer Gene Ther 2004, 11 (10), 643-64.

[96] Mingozzi, F.; High, K. A., Therapeutic in vivo gene transfer for genetic disease using AAV: progress and challenges. Nature reviews genetics 2011, 12 (5), 341-355.

[97] Naldini, L.; Blömer, U.; Gallay, P.; Ory, D.; Mulligan, R.; Gage, F. H.; Verma, I. M.; Trono, D., In vivo gene delivery and stable transduction of nondividing cells by a lentiviral vector. Science 1996, 272 (5259), 263-267.

[98] Gentner, B.; Schira, G.; Giustacchini, A.; Amendola, M.; Brown, B. D.; Ponzoni, M.; Naldini, L., Stable knockdown of microRNA in vivo by lentiviral vectors. Nature methods 2008, 6 (1), 63-66.

[99] Meloni, M.; Marchetti, M.; Garner, K.; Littlejohns, B.; Sala-Newby, G.; Xenophontos, N.; Floris, I.; Suleiman, M.-S.; Madeddu, P.; Caporali, A., Local inhibition of microRNA-24 improves reparative angiogenesis and left ventricle remodeling and function in mice with myocardial infarction. Molecular Therapy 2013.

[100] Xie, J.; Ameres, S. L.; Friedline, R.; Hung, J.-H.; Zhang, Y.; Xie, Q.; Zhong, L.; Su, Q.; He, R.; Li, M., Long-term, efficient inhibition of microRNA function in mice using rAAV vectors. Nature methods 2012, 9 (4), 403-409.

[101] Haraguchi, T.; Ozaki, Y.; Iba, H., Vectors expressing efficient RNA decoys achieve the long-term suppression of specific microRNA activity in mammalian cells. Nucleic acids research 2009, gkp040.

[102] Kay, M. A., State-of-the-art gene-based therapies: the road ahead. Nature Reviews Genetics 2011, $12(5), 316-328$.

[103] Scherr, M.; Venturini, L.; Battmer, K.; Schaller-Schoenitz, M.; Schaefer, D.; Dallmann, I.; Ganser, A.; Eder, M., Lentivirus-mediated antagomir expression for specific inhibition of miRNA function. Nucleic Acids Res 2007, 35 (22), e149.

[104] Jang, J. H.; Schaffer, D. V.; Shea, L. D., Engineering biomaterial systems to enhance viral vector gene delivery. Mol Ther 2011, 19 (8), 1407-15.

[105] Logg, C. R.; Logg, A.; Matusik, R. J.; Bochner, B. H.; Kasahara, N., Tissue-specific transcriptional targeting of a replication-competent retroviral vector. J Virol 2002, 76 (24), 12783-91.

[106] Mingozzi, F.; High, K. A., Immune responses to AAV vectors: overcoming barriers to successful gene therapy. Blood 2013, 122 (1), 23-36.

[107] Maheshri, N.; Koerber, J. T.; Kaspar, B. K.; Schaffer, D. V., Directed evolution of adeno-associated virus yields enhanced gene delivery vectors. Nat Biotechnol 2006, 24 (2), 198-204.

[108] Koerber, J. T.; Jang, J. H.; Schaffer, D. V., DNA shuffling of adeno-associated virus yields functionally diverse viral progeny. Mol Ther 2008, 16 (10), 1703-9.

[109] Knight, S.; Collins, M.; Takeuchi, Y., Insertional mutagenesis by retroviral vectors: current concepts and methods of analysis. Curr Gene Ther 2013, 13 (3), 211-27.

[110] Salvay, D. M.; Zelivyanskaya, M.; Shea, L. D., Gene delivery by surface immobilization of plasmid to tissue-engineering scaffolds. Gene Ther 2010, 17 (9), 1134-41.

[111] Adolph, E. J.; Nelson, C. E.; Werfel, T. A.; Guo, R.; Davidson, J. M.; Guelcher, S. A.; Duvall, C. L., Enhanced performance of plasmid DNA polyplexes stabilized by a combination of core hydrophobicity and surface PEGylation. J Mater Chem B 2014, 2 (46), 8154-8164.

[112] Nelson, C. E.; Kim, A. J.; Adolph, E. J.; Gupta, M. K.; Yu, F.; Hocking, K. M.; Davidson, J. M.; Guelcher, S. A.; Duvall, C. L., Tunable delivery of siRNA from a biodegradable scaffold to promote angiogenesis in vivo. Adv Mater 2014, 26 (4), 607-14, 506. 
[113] Castleberry, S.; Wang, M.; Hammond, P. T., Nanolayered siRNA dressing for sustained localized knockdown. ACS Nano 2013, 7 (6), 5251-61.

[114] Luo, D.; Saltzman, W. M., Synthetic DNA delivery systems. Nat Biotechno/ 2000, 18 (1), 33-7.

[115] Segura, T.; Shea, L. D., Surface-tethered DNA complexes for enhanced gene delivery. Bioconjug Chem 2002, 13 (3), 621-9.

[116] Shea, L. D.; Smiley, E.; Bonadio, J.; Mooney, D. J., DNA delivery from polymer matrices for tissue engineering. Nat Biotechnol 1999, 17 (6), 551-4.

[117] Jang, J.-H.; Schaffer, D. V.; Shea, L. D., Engineering Biomaterial Systems to Enhance Viral Vector Gene Delivery. Mol Ther 2011, 19 (8), 1407-1415.

[118] Thomson, D. W.; Bracken, C. P.; Szubert, J. M.; Goodall, G. J., On Measuring miRNAs after Transient Transfection of Mimics or Antisense Inhibitors. PLOS ONE 2013, 8 (1), e55214.

[119] Cui, L.; Liu, B.; Liu, G.; Zhang, W.; Cen, L.; Sun, J.; Yin, S.; Liu, W.; Cao, Y., Repair of cranial bone defects with adipose derived stem cells and coral scaffold in a canine model. Biomaterials 2007, 28 (36), 5477-86.

[120] Moioli, E. K.; Clark, P. A.; Xin, X.; Lal, S.; Mao, J. J., Matrices and scaffolds for drug delivery in dental, oral and craniofacial tissue engineering. Adv Drug Deliv Rev 2007, 59 (4-5), 308-24.

[121] Bose, S.; Roy, M.; Bandyopadhyay, A., Recent advances in bone tissue engineering scaffolds. Trends Biotechnol 2012, 30 (10), 546-54.

[122] Dumas, J. E.; Prieto, E. M.; Zienkiewicz, K. J.; Guda, T.; Wenke, J. C.; Bible, J.; Holt, G. E.; Guelcher, S. A., Balancing the rates of new bone formation and polymer degradation enhances healing of weight-bearing allograft/polyurethane composites in rabbit femoral defects. Tissue Eng Part $A$ 2014, 20 (1-2), 115-29.

[123] Priddy, L. B.; Chaudhuri, O.; Stevens, H. Y.; Krishnan, L.; Uhrig, B. A.; Willett, N. J.; Guldberg, R. E., Oxidized alginate hydrogels for bone morphogenetic protein-2 delivery in long bone defects. Acta Biomater 2014, 10 (10), 4390-9.

[124] Nguyen, M. K.; Jeon, O.; Krebs, M. D.; Schapira, D.; Alsberg, E., Sustained localized presentation of RNA interfering molecules from in situ forming hydrogels to guide stem cell osteogenic differentiation. Biomaterials 2014, 35 (24), 6278-86.

[125] Zou, D.; Zhang, Z.; He, J.; Zhang, K.; Ye, D.; Han, W.; Zhou, J.; Wang, Y.; Li, Q.; Liu, X.; Zhang, X.; Wang, S.; Hu, J.; Zhu, C.; Zhang, W.; zhou, Y.; Fu, H.; Huang, Y.; Jiang, X., Blood vessel formation in the tissue-engineered bone with the constitutively active form of HIF-1alpha mediated BMSCs. Biomaterials 2012, 33 (7), 2097-108.

[126] Zhang, W.; Wang, X.; Wang, S.; Zhao, J.; Xu, L.; Zhu, C.; Zeng, D.; Chen, J.; Zhang, Z.; Kaplan, D. L., The use of injectable sonication-induced silk hydrogel for VEGF $<$ sub $>165</$ sub $>$ and BMP-2 delivery for elevation of the maxillary sinus floor. Biomaterials 2011, 32 (35), 9415-9424.

[127] Xiao, W.; Fu, H.; Rahaman, M. N.; Liu, Y.; Bal, B. S., Hollow hydroxyapatite microspheres: a novel bioactive and osteoconductive carrier for controlled release of bone morphogenetic protein-2 in bone regeneration. Acta Biomater 2013, 9 (9), 8374-83.

[128] Kim, M. J.; Lee, B.; Yang, K.; Park, J.; Jeon, S.; Um, S. H.; Kim, D. I.; Im, S. G.; Cho, S. W., BMP-2 peptide-functionalized nanopatterned substrates for enhanced osteogenic differentiation of human mesenchymal stem cells. Biomaterials 2013, 34 (30), 7236-46.

[129] Ding, H.; Gao, Y.-S.; Hu, C.; Wang, Y.; Wang, C.-G.; Yin, J.-M.; Sun, Y.; Zhang, C.-Q., HIF-1 $\alpha$ Transgenic Bone Marrow Cells Can Promote Tissue Repair in Cases of Corticosteroid-Induced Osteonecrosis of the Femoral Head in Rabbits. PloS one 2013, 8 (5), e63628.

[130] Shen, X.; Wan, C.; Ramaswamy, G.; Mavalli, M.; Wang, Y.; Duvall, C. L.; Deng, L. F.; Guldberg, R. E.; Eberhart, A.; Clemens, T. L.; Gilbert, S. R., Prolyl hydroxylase inhibitors increase neoangiogenesis and callus formation following femur fracture in mice. J Orthop Res 2009, 27 (10), 1298-305. 
[131] Yau, W. W.; Rujitanaroj, P. O.; Lam, L.; Chew, S. Y., Directing stem cell fate by controlled RNA interference. Biomaterials 2012, 33 (9), 2608-28.

[132] Li, Y.; Fan, L.; Liu, S.; Liu, W.; Zhang, H.; Zhou, T.; Wu, D.; Yang, P.; Shen, L.; Chen, J., The promotion of bone regeneration through positive regulation of angiogenic-osteogenic coupling using microRNA-26a. Biomaterials 2013, 34 (21), 5048-5058.

[133] Murata, K.; Ito, H.; Yoshitomi, H.; Yamamoto, K.; Fukuda, A.; Yoshikawa, J.; Furu, M.; Ishikawa, M.; Shibuya, H.; Matsuda, S., Inhibition of miR-92a enhances fracture healing via promoting angiogenesis in a model of stabilized fracture in young mice. J Bone Miner Res 2014, 29 (2), 31626.

[134] Kosaka, N.; Iguchi, H.; Yoshioka, Y.; Hagiwara, K.; Takeshita, F.; Ochiya, T., Competitive interactions of cancer cells and normal cells via secretory microRNAs. J Biol Chem 2012, 287 (2), 1397-405.

[135] Suh, J. S.; Lee, J. Y.; Choi, Y. S.; Chung, C. P.; Park, Y. J., Peptide-mediated intracellular delivery of miRNA-29b for osteogenic stem cell differentiation. Biomaterials 2013, 34 (17), 4347-59.

[136] Deng, Y.; Wu, S.; Zhou, H.; Bi, X.; Wang, Y.; Hu, Y.; Gu, P.; Fan, X., Effects of a miR-31, Runx2, and Satb2 regulatory loop on the osteogenic differentiation of bone mesenchymal stem cells. Stem Cells Dev 2013, 22 (16), 2278-86.

[137] Deng, Y.; Bi, X.; Zhou, H.; You, Z.; Wang, Y.; Gu, P.; Fan, X., Repair of critical-sized bone defects with anti-miR-31-expressing bone marrow stromal stem cells and poly(glycerol sebacate) scaffolds. Eur Cell Mater 2014, 27, 13-24; discussion 24-5.

[138] Fausto, N., Liver regeneration. J Hepatol 2000, 32 (1 Suppl), 19-31.

[139] Bucher, N. L.; Farmer, S. R., Liver regeneration following partial hepatectomy: genes and metabolism. In Liver growth and repair, Springer: 1998; pp 3-27.

[140] Current U.S. Organ Transplant Waiting List. http://optn.transplant.hrsa.gov/latestData/rptData.asp (accessed September 6).

[141] Song, G.; Sharma, A. D.; Roll, G. R.; Ng, R.; Lee, A. Y.; Blelloch, R. H.; Frandsen, N. M.; Willenbring, H., MicroRNAs control hepatocyte proliferation during liver regeneration. Hepatology 2010, 51 (5), 1735-43.

[142] Pan, C.; Chen, H.; Wang, L.; Yang, S.; Fu, H.; Zheng, Y.; Miao, M.; Jiao, B., Down-regulation of MiR127 facilitates hepatocyte proliferation during rat liver regeneration. PLoS One 2012, 7 (6), e39151.

[143] Ranuncolo, S. M.; Polo, J. M.; Dierov, J.; Singer, M.; Kuo, T.; Greally, J.; Green, R.; Carroll, M.; Melnick, A., Bcl-6 mediates the germinal center B cell phenotype and lymphomagenesis through transcriptional repression of the DNA-damage sensor ATR. Nature Immunology 2007, 8 (7), 705714.

[144] Jørgensen, S.; Elvers, I.; Trelle, M. B.; Menzel, T.; Eskildsen, M.; Jensen, O. N.; Helleday, T.; Helin, K.; Sørensen, C. S., The histone methyltransferase SET8 is required for S-phase progression. The Journal of cell biology 2007, 179 (7), 1337-1345.

[145] Chen, H.; Sun, Y. M.; Dong, R. Q.; Yang, S. S.; Pan, C. Y.; Xiang, D.; Miao, M. Y.; Jiao, B. H., Mir-34a Is Upregulated during Liver Regeneration in Rats and Is Associated with the Suppression of Hepatocyte Proliferation. Plos One 2011, 6 (5), e20238.

[146] Little, M. H., Regrow or repair: potential regenerative therapies for the kidney. J Am Soc Nephrol 2006, 17 (9), 2390-401.

[147] Strutz, F.; Okada, H.; Lo, C. W.; Danoff, T.; Carone, R. L.; Tomaszewski, J. E.; Neilson, E. G., Identification and characterization of a fibroblast marker: FSP1. J Cell Biol 1995, 130 (2), 393-405.

[148] Witzgall, R.; Brown, D.; Schwarz, C.; Bonventre, J. V., Localization of Proliferating Cell Nuclear Antigen, Vimentin, C-Fos, and Clusterin in the Postischemic Kidney - Evidence for a Heterogenous Genetic Response among Nephron Segments, and a Large Pool of Mitotically Active and Dedifferentiated Cells. Journal of Clinical Investigation 1994, 93 (5), 2175-2188. 
[149] Bonventre, J. V., Dedifferentiation and proliferation of surviving epithelial cells in acute renal failure. J Am Soc Nephrol 2003, 14 Suppl 1 (suppl 1), S55-61.

[150] Imasawa, T.; Utsunomiya, Y.; Kawamura, T.; Zhong, Y.; Nagasawa, R.; Okabe, M.; Maruyama, N.; Hosoya, T.; Ohno, T., The potential of bone marrow-derived cells to differentiate to glomerular mesangial cells. J Am Soc Nephrol 2001, 12 (7), 1401-9.

[151] Poulsom, R.; Forbes, S. J.; Hodivala-Dilke, K.; Ryan, E.; Wyles, S.; Navaratnarasah, S.; Jeffery, R.; Hunt, T.; Alison, M.; Cook, T.; Pusey, C.; Wright, N. A., Bone marrow contributes to renal parenchymal turnover and regeneration. J Pathol 2001, 195 (2), 229-35.

[152] Cantaluppi, V.; Gatti, S.; Medica, D.; Figliolini, F.; Bruno, S.; Deregibus, M. C.; Sordi, A.; Biancone, L.; Tetta, C.; Camussi, G., Microvesicles derived from endothelial progenitor cells protect the kidney from ischemia-reperfusion injury by microRNA-dependent reprogramming of resident renal cells. Kidney Int 2012, 82 (4), 412-27.

[153] Kato, M.; Zhang, J.; Wang, M.; Lanting, L.; Yuan, H.; Rossi, J. J.; Natarajan, R., MicroRNA-192 in diabetic kidney glomeruli and its function in TGF-beta-induced collagen expression via inhibition of E-box repressors. PNAS 2007, 104 (9), 3432-7.

[154] Kato, M.; Arce, L.; Natarajan, R., MicroRNAs and Their Role in Progressive Kidney Diseases. Clinical Journal of the American Society of Nephrology 2009, 4 (7), 1255-1266.

[155] Elmen, J.; Lindow, M.; Schutz, S.; Lawrence, M.; Petri, A.; Obad, S.; Lindholm, M.; Hedtjarn, M.; Hansen, H. F.; Berger, U.; Gullans, S.; Kearney, P.; Sarnow, P.; Straarup, E. M.; Kauppinen, S., LNAmediated microRNA silencing in non-human primates. Nature 2008, 452 (7189), 896-9.

[156] Long, J. Y.; Wang, Y.; Wang, W. J.; Chang, B. H. J.; Danesh, F. R., Identification of MicroRNA-93 as a Novel Regulator of Vascular Endothelial Growth Factor in Hyperglycemic Conditions. Journal of Biological Chemistry 2010, 285 (30), 23455-23463.

[157] Zarjou, A.; Yang, S.; Abraham, E.; Agarwal, A.; Liu, G., Identification of a microRNA signature in renal fibrosis: role of miR-21. Am J Physiol Renal Physiol 2011, 301 (4), F793-801.

[158] Putta, S.; Lanting, L.; Sun, G.; Lawson, G.; Kato, M.; Natarajan, R., Inhibiting microRNA-192 ameliorates renal fibrosis in diabetic nephropathy. J Am Soc Nephrol 2012, 23 (3), 458-69.

[159] Luo, W.; Nie, Q.; Zhang, X., MicroRNAs involved in skeletal muscle differentiation. Journal of genetics and genomics = Yi chuan xue bao 2013, 40 (3), 107-16.

[160] Lepper, C.; Partridge, T. A.; Fan, C. M., An absolute requirement for Pax7-positive satellite cells in acute injury-induced skeletal muscle regeneration. Development 2011, 138 (17), 3639-46.

[161] Sambasivan, R.; Yao, R.; Kissenpfennig, A.; Van Wittenberghe, L.; Paldi, A.; Gayraud-Morel, B.; Guenou, H.; Malissen, B.; Tajbakhsh, S.; Galy, A., Pax7-expressing satellite cells are indispensable for adult skeletal muscle regeneration. Development 2011, 138 (17), 3647-56.

[162] Murphy, M. M.; Lawson, J. A.; Mathew, S. J.; Hutcheson, D. A.; Kardon, G., Satellite cells, connective tissue fibroblasts and their interactions are crucial for muscle regeneration. Development 2011, 138 (17), 3625-3637.

[163] Liu, N.; Williams, A. H.; Maxeiner, J. M.; Bezprozvannaya, S.; Shelton, J. M.; Richardson, J. A.; Bassel-Duby, R.; Olson, E. N., microRNA-206 promotes skeletal muscle regeneration and delays progression of Duchenne muscular dystrophy in mice. J Clin Invest 2012, 122 (6), 2054-65.

[164] Williams, A. H.; Valdez, G.; Moresi, V.; Qi, X.; McAnally, J.; Elliott, J. L.; Bassel-Duby, R.; Sanes, J. R.; Olson, E. N., MicroRNA-206 delays ALS progression and promotes regeneration of neuromuscular synapses in mice. Science 2009, 326 (5959), 1549-54.

[165] Yan, B.; Guo, J. T.; Zhu, C. D.; Zhao, L. H.; Zhao, J. L., miR-203b: a novel regulator of MyoD expression in tilapia skeletal muscle. J Exp Biol 2013, 216 (Pt 3), 447-51.

[166] Bonow, R. O.; Mann, D. L.; Zipes, D. P.; Libby, P., Braunwald's Heart Disease: A Textbook of Cardiovascular Medicine. Elsevier Health Sciences: 2011. 
[167] Wahlquist, C.; Jeong, D.; Rojas-Munoz, A.; Kho, C.; Lee, A.; Mitsuyama, S.; van Mil, A.; Park, W. J.; Sluijter, J. P.; Doevendans, P. A.; Hajjar, R. J.; Mercola, M., Inhibition of miR-25 improves cardiac contractility in the failing heart. Nature 2014, 508 (7497), 531-5.

[168] Wahlquist, C.; Jeong, D.; Rojas-Muñoz, A.; Kho, C.; Lee, A.; Mitsuyama, S.; van Mil, A.; Park, W. J.; Sluijter, J. P.; Doevendans, P. A., Inhibition of miR-25 improves cardiac contractility in the failing heart. Nature 2014, 508 (7497), 531-535.

[169] Meloni, M.; Marchetti, M.; Garner, K.; Littlejohns, B.; Sala-Newby, G.; Xenophontos, N.; Floris, I.; Suleiman, M. S.; Madeddu, P.; Caporali, A.; Emanueli, C., Local inhibition of microRNA-24 improves reparative angiogenesis and left ventricle remodeling and function in mice with myocardial infarction. Mol Ther 2013, 21 (7), 1390-402.

[170] Small, E. M.; Frost, R. J.; Olson, E. N., MicroRNAs add a new dimension to cardiovascular disease. Circulation 2010, 121 (8), 1022-32.

[171] Wang, C.; Wang, S.; Zhao, P.; Wang, X.; Wang, J.; Wang, Y.; Song, L.; Zou, Y.; Hui, R., MiR-221 promotes cardiac hypertrophy in vitro through the modulation of p27 expression. Journal of cellular biochemistry 2012, 113 (6), 2040-2046.

[172] van Rooij, E.; Sutherland, L. B.; Qi, X.; Richardson, J. A.; Hill, J.; Olson, E. N., Control of stressdependent cardiac growth and gene expression by a microRNA. Science 2007, 316 (5824), 575-9.

[173] van Rooij, E.; Marshall, W. S.; Olson, E. N., Toward microRNA-based therapeutics for heart disease: the sense in antisense. Circ Res 2008, 103 (9), 919-28.

[174] Caporali, A.; Meloni, M.; Vollenkle, C.; Bonci, D.; Sala-Newby, G. B.; Addis, R.; Spinetti, G.; Losa, S.; Masson, R.; Baker, A. H.; Agami, R.; le Sage, C.; Condorelli, G.; Madeddu, P.; Martelli, F.; Emanueli, C., Deregulation of microRNA-503 contributes to diabetes mellitus-induced impairment of endothelial function and reparative angiogenesis after limb ischemia. Circulation 2011, 123 (3), 282-91.

[175] Doebele, C.; Bonauer, A.; Fischer, A.; Scholz, A.; Reiss, Y.; Urbich, C.; Hofmann, W. K.; Zeiher, A. M.; Dimmeler, S., Members of the microRNA-17-92 cluster exhibit a cell-intrinsic antiangiogenic function in endothelial cells. Blood 2010, 115 (23), 4944-50.

[176] Roy, S.; Sen, C. K., miRNA in wound inflammation and angiogenesis. Microcirculation 2012, 19 (3), 224-32.

[177] Banerjee, J.; Chan, Y. C.; Sen, C. K., MicroRNAs in skin and wound healing. Physiol Genomics 2011, 43 (10), 543-56.

[178] Mills, S. J.; Cowin, A. J., MicrorNAs and their roles in wound repair and regeneration. Wound Practice \& Research: Journal of the Australian Wound Management Association 2013, 21 (1), 26.

[179] Funari, V. A.; Winkler, M.; Brown, J.; Dimitrijevich, S. D.; Ljubimov, A. V.; Saghizadeh, M., Differentially expressed wound healing-related microRNAs in the human diabetic cornea. PLOS One 2013, 8 (12), e84425.

[180] Hezova, R.; Slaby, O.; Faltejskova, P.; Mikulkova, Z.; Buresova, I.; Raja, K. R.; Hodek, J.; Ovesna, J.; Michalek, J., microRNA-342, microRNA-191 and microRNA-510 are differentially expressed in T regulatory cells of type 1 diabetic patients. Cell Immunol 2010, 260 (2), 70-4.

[181] Sand, M.; Gambichler, T.; Sand, D.; Skrygan, M.; Altmeyer, P.; Bechara, F. G., MicroRNAs and the skin: tiny players in the body's largest organ. J Dermatol Sci 2009, 53 (3), 169-75.

[182] Pastar, I.; Khan, A. A.; Stojadinovic, O.; Lebrun, E. A.; Medina, M. C.; Brem, H.; Kirsner, R. S.; Jimenez, J. J.; Leslie, C.; Tomic-Canic, M., Induction of specific microRNAs inhibits cutaneous wound healing. J Biol Chem 2012, 287 (35), 29324-35.

[183] Wetzler, C.; Kampfer, H.; Stallmeyer, B.; Pfeilschifter, J.; Frank, S., Large and sustained induction of chemokines during impaired wound healing in the genetically diabetic mouse: prolonged persistence of neutrophils and macrophages during the late phase of repair. J Invest Dermatol 2000, 115 (2), 245-53. 
[184] Graves, D.; Dasu, M. R., Advances in Wound Care: Volume 2 Inflammation Impairs Wound Healing in Diabetic Mice. 2011.

[185] Tili, E.; Michaille, J. J.; Cimino, A.; Costinean, S.; Dumitru, C. D.; Adair, B.; Fabbri, M.; Alder, H.; Liu, C. G.; Calin, G. A.; Croce, C. M., Modulation of miR-155 and miR-125b Levels following Lipopolysaccharide/TNF- Stimulation and Their Possible Roles in Regulating the Response to Endotoxin Shock. The Journal of Immunology 2007, 179 (8), 5082-5089.

[186] Murphy, A. J.; Guyre, P. M.; Pioli, P. A., Estradiol suppresses NF-kB activation through coordinated regulation of let-7a and miR-125b in primary human macrophages. The Journal of Immunology 2010, 184 (9), 5029-5037.

[187] Brown, P. N.; Yin, H., PNA-based microRNA inhibitors elicit anti-inflammatory effects in microglia cells. Chem Commun (Camb) 2013, 49 (39), 4415-7.

[188] Li, H.; Chang, L.; Du, W. W.; Gupta, S.; Khorshidi, A.; Sefton, M.; Yang, B. B., Anti-microRNA-378a enhances wound healing process by upregulating integrin beta-3 and vimentin. Mol Ther 2014, 22 (10), 1839-50.

[189] Feng, B.; Chen, S.; Zhang, L.; Cao, Y.; Chakrabarti, S., miRNA-146a and miRNA-200b Antagomirs Accelerate Wound Healing through the Regulation of VEGF and Fibronectin. Journal of Pharmacy and Pharmacology 2014, 2, 104-113.

[190] Feng, B.; Chen, S.; McArthur, K.; Wu, Y.; Sen, S.; Ding, Q.; Feldman, R. D.; Chakrabarti, S., miR146a-Mediated Extracellular Matrix Protein Production in Chronic Diabetes Complications. Diabetes 2011, 60 (11), 2975-2984.

[191] McArthur, K.; Feng, B.; Wu, Y.; Chen, S.; Chakrabarti, S., MicroRNA-200b Regulates Vascular Endothelial Growth Factor-Mediated Alterations in Diabetic Retinopathy. Diabetes 2011, 60 (4), 1314-1323.

[192] Biswas, S.; Roy, S.; Banerjee, J.; Hussain, S. R.; Khanna, S.; Meenakshisundaram, G.; Kuppusamy, P.; Friedman, A.; Sen, C. K., Hypoxia inducible microRNA 210 attenuates keratinocyte proliferation and impairs closure in a murine model of ischemic wounds. PNAS 2010, 107 (15), 6976-81.

[193] Sundaram, G. M.; Common, J. E. A.; Gopal, F. E.; Srikanta, S.; Lakshman, K.; Lunny, D. P.; Lim, T. C.; Tanavde, V.; Lane, E. B.; Sampath, P., 'See-saw' expression of microRNA-198 and FSTL1 from a single transcript in wound healing. Nature 2013, 495 (7439), 103-106.

[194] Poliseno, L.; Tuccoli, A.; Mariani, L.; Evangelista, M.; Citti, L.; Woods, K.; Mercatanti, A.; Hammond, S.; Rainaldi, G., MicroRNAs modulate the angiogenic properties of HUVECs. 2006; Vol. 108, p 30683071.

[195] Wang, X. H.; Qian, R. Z.; Zhang, W.; Chen, S. F.; Jin, H. M.; Hu, R. M., MicroRNA-320 expression in myocardial microvascular endothelial cells and its relationship with insulin-like growth factor- 1 in type 2 diabetic rats. Clin Exp Pharmacol Physiol 2009, 36 (2), 181-8.

[196] Choi, Y. C.; Yoon, S.; Jeong, Y.; Yoon, J.; Baek, K., Regulation of vascular endothelial growth factor signaling by miR-200b. Mol Cells 2011, 32 (1), 77-82.

[197] Chan, Y. C.; Khanna, S.; Roy, S.; Sen, C. K., miR-200b targets Ets-1 and is down-regulated by hypoxia to induce angiogenic response of endothelial cells. J Biol Chem 2011, 286 (3), 2047-56.

[198] Caporali, A.; Meloni, M.; Völlenkle, C.; Bonci, D.; Sala-Newby, G. B.; Addis, R.; Spinetti, G.; Losa, S.; Masson, R.; Baker, A. H., Deregulation of microRNA-503 contributes to diabetes mellitus-induced impairment of endothelial function and reparative angiogenesis after limb ischemia. Circulation 2011, 123 (3), 282-291.

[199] Doebele, C.; Bonauer, A.; Fischer, A.; Scholz, A.; Reiss, Y.; Urbich, C.; Hofmann, W.-K.; Zeiher, A. M.; Dimmeler, S., Members of the microRNA-17-92 cluster exhibit a cell-intrinsic antiangiogenic function in endothelial cells. Blood 2010, 115 (23), 4944-4950.

[200] Murata, K.; Ito, H.; Yoshitomi, H.; Yamamoto, K.; Fukuda, A.; Yoshikawa, J.; Furu, M.; Ishikawa, M.; Shibuya, H.; Matsuda, S., Inhibition of miR-92a Enhances Fracture Healing via Promoting 
Angiogenesis in a Model of Stabilized Fracture in Young Mice. Journal of Bone and Mineral Research 2014, 29 (2), 316-326.

[201] Larson, B. J.; Longaker, M. T.; Lorenz, H. P., Scarless fetal wound healing: a basic science review. Plast Reconstr Surg 2010, 126 (4), 1172-80.

[202] Cheng, J.; Yu, H.; Deng, S.; Shen, G., MicroRNA profiling in mid- and late-gestational fetal skin: implication for scarless wound healing. Tohoku J Exp Med 2010, 221 (3), 203-9.

[203] Yin, V. P.; Thomson, J. M.; Thummel, R.; Hyde, D. R.; Hammond, S. M.; Poss, K. D., Fgf-dependent depletion of microRNA-133 promotes appendage regeneration in zebrafish. Genes Dev 2008, 22 (6), 728-33.

[204] Bowen, T.; Jenkins, R. H.; Fraser, D. J., MicroRNAs, transforming growth factor beta-1, and tissue fibrosis. J Pathol 2013, 229 (2), 274-85.

[205] Chau, B. N.; Xin, C.; Hartner, J.; Ren, S.; Castano, A. P.; Linn, G.; Li, J.; Tran, P. T.; Kaimal, V.; Huang, X.; Chang, A. N.; Li, S.; Kalra, A.; Grafals, M.; Portilla, D.; MacKenna, D. A.; Orkin, S. H.; Duffield, J. S., MicroRNA-21 promotes fibrosis of the kidney by silencing metabolic pathways. Sci Trans/ Med 2012, 4 (121), 121ra18.

[206] Thum, T.; Gross, C.; Fiedler, J.; Fischer, T.; Kissler, S.; Bussen, M.; Galuppo, P.; Just, S.; Rottbauer, W.; Frantz, S.; Castoldi, M.; Soutschek, J.; Koteliansky, V.; Rosenwald, A.; Basson, M. A.; Licht, J. D.; Pena, J. T.; Rouhanifard, S. H.; Muckenthaler, M. U.; Tuschl, T.; Martin, G. R.; Bauersachs, J.; Engelhardt, S., MicroRNA-21 contributes to myocardial disease by stimulating MAP kinase signalling in fibroblasts. Nature 2008, 456 (7224), 980-4.

[207] Liu, G.; Friggeri, A.; Yang, Y.; Milosevic, J.; Ding, Q.; Thannickal, V. J.; Kaminski, N.; Abraham, E., miR-21 mediates fibrogenic activation of pulmonary fibroblasts and lung fibrosis. J Exp Med 2010, 207 (8), 1589-97.

[208] Wang, T.; Feng, Y.; Sun, H.; Zhang, L.; Hao, L.; Shi, C.; Wang, J.; Li, R.; Ran, X.; Su, Y.; Zou, Z., miR-21 Regulates Skin Wound Healing by Targeting Multiple Aspects of the Healing Process. The American Journal of Pathology 2012, 181 (6), 1911-1920.

[209] van Rooij, E.; Purcell, A. L.; Levin, A. A., Developing microRNA therapeutics. Circ Res 2012, 110 (3), 496-507.

[210] Hydbring, P.; Badalian-Very, G., Clinical applications of microRNAs. F1000Res 2013, 2, 136.

[211] Gabriely, G.; Wurdinger, T.; Kesari, S.; Esau, C. C.; Burchard, J.; Linsley, P. S.; Krichevsky, A. M., MicroRNA 21 promotes glioma invasion by targeting matrix metalloproteinase regulators. Mol Cell Biol 2008, 28 (17), 5369-80.

[212] Koval, E. D.; Shaner, C.; Zhang, P.; du Maine, X.; Fischer, K.; Tay, J.; Chau, B. N.; Wu, G. F.; Miller, T. M., Method for widespread microRNA-155 inhibition prolongs survival in ALS-model mice. Hum Mol Genet 2013, 22 (20), 4127-35.

[213] Grueter, C. E.; van Rooij, E.; Johnson, B. A.; DeLeon, S. M.; Sutherland, L. B.; Qi, X.; Gautron, L.; Elmquist, J. K.; Bassel-Duby, R.; Olson, E. N., A cardiac microRNA governs systemic energy homeostasis by regulation of MED13. Cell 2012, 149 (3), 671-83.

[214] Montgomery, R. L.; Hullinger, T. G.; Semus, H. M.; Dickinson, B. A.; Seto, A. G.; Lynch, J. M.; Stack, C.; Latimer, P. A.; Olson, E. N.; van Rooij, E., Therapeutic inhibition of miR-208a improves cardiac function and survival during heart failure. Circulation 2011, 124 (14), 1537-47.

[215] Porrello, E. R.; Mahmoud, A. I.; Simpson, E.; Johnson, B. A.; Grinsfelder, D.; Canseco, D.; Mammen, P. P.; Rothermel, B. A.; Olson, E. N.; Sadek, H. A., Regulation of neonatal and adult mammalian heart regeneration by the miR-15 family. PNAS 2013, 110 (1), 187-92. 


\section{Graphical Abstract}

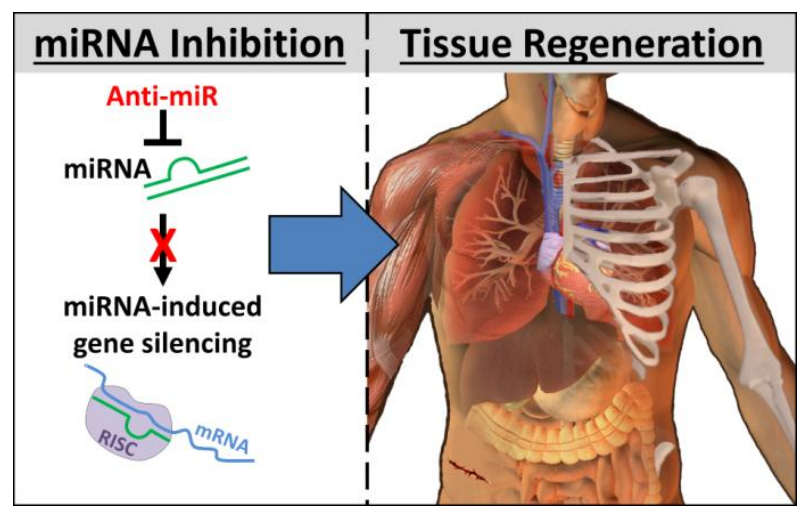

